\title{
SIGNIFICADOS DIVERGENTES DE LO «POPULAR». SARMIENTO, SASTRE Y SUS ALIADOS EN LA EDUCACIÓN PRIMARIA DE LA CIUDAD DE BUENOS AIRES DURANTE EL PERÍODO LIBERAL TEMPRANO (1852-1872)
}

\author{
Divergent Meanings of the "Popular». Sarmiento, Sastre and their \\ allies in the field of primary education of the City of Buenos Aires \\ during the early liberal era (1852-1872)
}

\section{Marcelo Caruso* y Marco Rodríguez Wehrmeister\&}

Fecha de recepción: 22/01/2017 • Fecha de aceptación: 25/04/2017

Resumen. El presente trabajo analiza las cambiantes políticas escolares de la ciudad de Buenos Aires entre la caída del régimen de Juan Manuel de Rosas en 1852 y la consolidación de lineamientos curriculares para las escuelas de la ciudad en 1872. Las políticas escolares locales fueron erráticas, incluso conflictivas, en sus prioridades y estuvieron signadas por diversos grupos de actores sociales y educativos. Se interpretan las diversas estrategias y la creciente formación de facciones en la administración escolar local como resultado de un posicionamiento diferenciado de estos actores en torno a la cuestión de los significados de lo «popular», significados que afectaban tanto la esfera política como la esfera educativa. En este marco, la fracción liberal en torno a Sarmiento mantuvo una fuerte politicidad de lo popular, lo cual incluyó tanto una fuerte confianza en la participación social en la regulación y el mejoramiento de las escuelas como una preocupación consecuente por la expansión escolar. Una fracción diferenciada, ligada al liberalismo católico y que tuvo en el escritor y pedagogo Marcos Sastre su figura central, planteaba una visión distante de lo popular en relación al campo de la educación y se centró en cuestiones técnico-pedagógicas más que políticas.

\footnotetext{
"Instituto de Ciencias de la Educación, Facultad de Ciencias Sociales, Estudios Culturales y de la Educación, Universidad Humboldt, Berlin. Unter den Linden 6 (Sitz: GS7) 10099 Berlin/Alemania. marcelo.caruso@hu-berlin.de

\& Instituto de Sociología, Facultad de Humanidades, Universidad de Valparaíso, Chile. Calle Serrano N.54, Valparaíso, Chile. marco.rodriguez@uv.cl
}

Cómo citar este artículo: Caruso, Marcelo y Marco Rodríguez Wehrmeister, «Significados divergentes de lo "popular". Sarmiento, Sastre y sus aliados en la educación primaria de la ciudad de Buenos Aires durante el período liberal temprano (1852-1872)». Historia y Memoria de la Educación 7 (2018): 423-465. 
Palabras clave: Educación popular; Política escolar; Domingo F. Sarmiento; Marcos Sastre; Liberalismo.

Abstract. This article analyses the changing school policies in the city of Buenos Aires between the fall of Juan Manuel de Rosas' regime and the imposition of a unified curriculum in the city in 1872. Local school policies were erratic and even conflicting in their priorities and were influenced by different social and educational groups. Different strategies and the emergence of educational factions within the school administration are seen as being largely the result of different postures regarding the crucial issue of the meanings of the "popular». These meanings affected both the political and the educational spheres. In this constellation, a liberal faction led by Sarmiento maintained the strong political meanings associated with the popular, which included a strong confidence in the active participation of civil society in the regulation and improvement of the schools as well as a consistent concern about the extension of school attendance. Another faction was rather Catholic in its liberalism and had in Marcos Sastre, a writer and educationist, its central figure. This faction defended a sceptical perspective about the popular in the field of education and focused on pedagogical issues to the detriment of a more political approach.

Keywords: Popular education; School policy; Domingo F. Sarmiento; Marcos Sastre; Liberalism.

\section{LIBERALISMO, PUEBLO Y EDUCACIÓN}

Cuando en 1866 un «catecismo político» se publicó para el uso de las escuelas de Buenos Aires, el prólogo hacía una fuerte evocación a las posturas liberales iniciales sobre el nuevo orden constitucional y republicano:

Creemos que al niño y al niño de estos paises con mas especialidad, débesele inculcar con las primeras nociones de Dios, de religion, de humanidad, las de patria, Democracia y República que forman otra religion que amplia y complementa la primera faz de la educacion del futuro ciudadano. ${ }^{1}$

La educación del pueblo aún ocupaba una posición muy alta en la retórica de los liberales porteños a mediados del siglo XIX. La idea de que

\footnotetext{
${ }^{1}$ Catecismo politico al uso de las escuelas de Buenos Aires (Buenos Aires: Imprenta de El Orden, 1866), 3.
} 
«la paz pública» nunca pueda ser perturbada «salvo que el pueblo lo tolere o apoye» fue, en las décadas posteriores al régimen autoritario de Juan Manuel de Rosas (1793-1877), un asunto político urgente en la pujante ciudad de Buenos Aires. ${ }^{2} \mathrm{El}$ "pueblo» como el agente prometedor de soberanía y, al mismo tiempo, como una cruda realidad a ser enfrentada por las élites liberales, tenía que ser reorganizado/reeducado, si el gobierno republicano y la sociedad democrática pretendían consolidarse.

El vínculo entre la educación moderna de masas, el pueblo y el cambio político no fue, en absoluto, un desarrollo meramente local y específico de Buenos Aires, sino un fenómeno que afectaba a todas las formas de gobierno desde la modernidad temprana. Todos los significados atribuidos al pueblo tuvieron consecuencias palpables sobre la forma de la institución educativa moderna. La celebración conservadora de un pueblo cristiano devoto; la abstracción liberal de un pueblo habilitado con el derecho a la soberanía; la redefinición socialista del pueblo como la «clase trabajadora»; la concepción fascista de pueblo superior en la escala de la civilización, o en la jerarquía de las «razas» y muchas otras caracterizaciones del pueblo han sido cruciales en la elaboración de una propuesta de educación «popular».

Teniendo en cuenta los significados de lo popular asociados al avance institucional de la educación primaria, se propone explicar la dinámica institucional confusa y cambiante de la educación elemental en la ciudad de Buenos Aires del liberalismo temprano. El análisis de los significados asociados a la educación popular entre el final del régimen de Rosas en 1852 y la consolidación definitiva de una agencia local de gobierno educativo en las regulaciones escolares para la ciudad en 1872 apunta a los proyectos alternativos dentro de las fuerzas liberales en relación a nuevas formas de institucionalización de la educación. Se trata de una época de suma conflictividad en torno a los lineamientos de la organización del país. La Provincia de Buenos Aires, por ejemplo, se separó de la Confederación Argentina entre 1853 y 1860. Los conflictos en torno a la federalización de la Ciudad de Buenos Aires como capital del país y su definitiva separación de la Provincia de Buenos Aires recién se resolverían en el año 1880.

\footnotetext{
${ }^{2}$ Principios de gobierno para el uso de las escuelas del Estado de Buenos Aires (Buenos Aires: Imprenta Argentina, 1860), 4.
} 
Considerando que la historiografía ha dado cuenta de gran parte del debate ideológico entre los proyectos más democráticos y los más utilitaristas de integración del pueblo en el nuevo periodo después de Rosas, ${ }^{3}$ el proceso propiamente dicho de institucionalización en estas décadas cruciales de la toma liberal del poder no ha sido abordado de manera sistemática. La historiografía educacional, en cierta medida, descuidó el análisis del proceso de creación de nuevas agencias de gobierno educativo y el rol jugado por intelectuales y políticos relevantes del país. Si bien el rol de estos intelectuales como escritores es bien conocido, su rol en la elaboración de políticas no ha sido abordado con la misma intensidad. En este nivel de institucionalización, donde la contención del pueblo parecía fundamental para la supervivencia del orden liberal aún frágil, una serie de diferencias emergieron dentro del propio liberalismo porteño. ${ }^{4}$ Por cierto, el problema de la adaptación del pueblo al imperativo político de los nuevos tiempos había sido un asunto recurrente de la escena política argentina desde la independencia. Identidades amenazantes como la de los montoneros y otras formas de insurrección popular ${ }^{5}$ actuaron en el marco de los patrones heredados de significados del "pueblo» y lo "popular». Por consiguiente, en el presente artículo se delineará brevemente la cuestión de lo popular en los tiempos posteriores a la independencia, para presentar después las posiciones diferenciadas al interior del dominante liberalismo de la ciudad de Buenos Aires después de la caída del régimen de Juan Manuel de Rosas en 1852. Siguiendo en esta línea de argumentación, la vinculación entre pueblo y educación dentro de este liberalismo dominante fue también diferenciada, y esto contribuyó —en nuestra hipótesis - en la configuración de una política escolar para la Ciudad de Buenos Aires particularmente errática y conflictiva que alcanzó a elementos tales como la cuestión de la formación docente, los textos y el mobiliario escolar. En suma, se presentará en el presente trabajo un intento de explicación de las dificultades del liberalismo rioplatense

\footnotetext{
${ }^{3}$ Natalio Botana, La tradición republicana (Buenos Aires: Editorial Sudamericana, 1997); Tulio Halperin Donghi, Una nación para el desierto argentino (Buenos Aires: CEAL, 1992); Susana Villavicencio, Sarmiento y la nación cívica. Ciudadanía y filosofías de la nación en Argentina (Buenos Aires: Eudeba, 2008).

${ }^{4}$ Véase la carta de Benjamin Lenoir, uno de los cuñados de Sarmiento, al gobernador de la provincia de Mendoza, 1 de mayo, 1867, Museo Mitre, Fondo General Wenceslao Paunero.

${ }^{5}$ Véase el todavía trabajo innovador de Ariel de la Fuente, Children of Facundo. Caudillo and Gaucho Insurgency During the Argentine State-Formation Process (La Rioja, 1853-1870) (Durham \& Londres: Duke University Press, 2000).
} 
en generar un sistema escolar de amplia participación popular pero que programáticamente se centraba en el pueblo.

\section{EL «PUEBLO» DESPUÉS DE LA REVOLUCIÓN Y LA INDEPENDENCIA}

Mariano Narodowski ha caracterizado los inicios del siglo XIX en la historiografía de la educación argentina como el «lado oscuro de la luna». El enfoque de la historiografía educacional sobre la construcción del sistema de educación nacional moderno desde 1884 en adelante, según su tesis, pasó por alto los desarrollos previos en el establecimiento de la escolarización moderna. ${ }^{6} \mathrm{El}$ mismo Narodowski ha analizado las primeras políticas educativas del Estado de Buenos Aires de la década de 1820. En este sentido, puede sostenerse que el lado oscuro de la historiografía reciente de la educación de la ciudad de Buenos Aires son las décadas entre el ascenso de Juan Manuel de Rosas al poder en 1829 y la consolidación del estado nacional como agente educativo después de $1884 .{ }^{7}$ Particularmente, el intrincado panorama educativo del liberalismo temprano posterior a la caída de Rosas ha generado poca atención historiográfica.

El primer aspecto destacable de las políticas educativas locales en la ciudad y provincia de Buenos Aires después de 1852 fue la clara continuidad con las estructuras e instituciones que entraron en funcionamiento en la década de 1820 y que fueron interrumpidas en muchos aspectos bajo el gobierno de Rosas en las décadas de 1830 y 1840. El modelo francés, en el que se inspiró el gobierno del sector educacional dependiente de la universidad, al que el entonces influyente ministro Bernardino Rivadavia (1780-1845) había favorecido en 1822, fue rápidamente reintroducido a través de un decreto del 26 de octubre de $1852 .{ }^{8}$ La supervisión e inspección de las escuelas primarias de niños urbanas y rurales por parte de la universidad fue complementada por otra institución ya conocida, independiente de la universidad y con fuerte peso en la oferta escolar:

\footnotetext{
${ }^{6}$ Mariano Narodowski, «El lado oscuro de la luna. El temprano siglo xix y la historiografía educacional argentina», Historia de la educación en debate, (1996), 269-280.

${ }^{7}$ Raúl Veiga, «La instrucción pública elemental y la organización nacional. Argentina, 1810-1880». En École et société en Espagne et en Amérique Latine (XVIIIe-XXe siècles), (1983), 103-118.

8 Juan P. Ramos, Historia de la instrucción primaria en la República Argentina, 1810-1910, vol. 2. (Peuser: Buenos Aires, 1910), 3.
} 
la Sociedad de Beneficencia, fundada originalmente en $1823 .{ }^{9}$ Esta Sociedad, la cual había sobrevivido de manera informal a los difíciles años bajo el gobierno de Rosas, había sido restablecida el 16 de marzo de 1852 volviéndose a hacer cargo de todas las escuelas de niñas de la provincia. ${ }^{10}$ Sobre esta base, escuelas públicas fueron creadas rápidamente después de 1852, cuando solo existían tres escuelas públicas para cada sexo en la ciudad. ${ }^{11}$ Ya un año más tarde, once escuelas de hombres y cinco escuelas de mujeres estaban funcionando. El aumento constante del número de escuelas y de la matrícula fue evidente y en 1864 —el último año del período para el cual hay datos estadísticos disponibles-, existían 25 escuelas de hombres (algunas de éstas eran para ambos sexos) y 20 escuelas de mujeres. ${ }^{12}$ El número de niños que asistía a estas escuelas casi se cuadruplicó de 1852 a 1864 .

Estos pasos iniciales de la reconstrucción del gobierno educativo sobre la senda de la gestión diferenciada por género pusieron de manifiesto la opinión generalizada que el desarrollo de la provincia de Buenos Aires, y el futuro general del país, tenía que, de alguna manera, proseguir los «años dorados» de reforma liberal bajo Rivadavia. Que las élites porteñas miraran aquel período en el momento de diseñar el nuevo gobierno de la educación popular tuvo consecuencias de amplio alcance porque la década de 1820 había presenciado un importante cambio en el significado del concepto de "pueblo» y de lo "popular». El término pueblo, tradicionalmente comprendido para designar unidades políticas diferentes y usado en plural, era desafiado por un concepto unificado de pueblo que devino la fuente única del gobierno legítimo en el republicanismo temprano. ${ }^{13}$ Otros significados similares para designar a la población existían, pero la decisión tomada por las élites respecto a la instalación de un gobierno representativo basado sobre el derecho a sufragio general masculino en

\footnotetext{
${ }^{9}$ Sociedad de Beneficencia de la Capital, Sociedad de Beneficencia de la Capital. Su origen y su desenvolvimiento, 1823-1923 (Buenos Aires: Talleres gráficos del Asilo de Huérfanos, 1923).

${ }^{10}$ Véase el decreto N. ${ }^{\circ} 2061$ en Registro oficial del gobierno de Buenos-Aires, vol. 31 (1852): 55-57.

${ }^{11}$ Carlos Newland, Buenos Aires no es Pampa: la educación elemental porteña, 1820-1860 (Buenos Aires: GEL, 1992), 150.

${ }^{12}$ Véase «Provincia de Buenos Aires» y «Escuelas de niñas á cargo de la Sociedad de Beneficencia en los años de 1861, 1862 y 1864», Rejistro estadístico de la República Arjentina, (1865), 179 y 181 respectivamente.

${ }^{13}$ Sobre este cambio en América Latina: Fátima Sá e Melo Ferreira, «Povo e povos no mundo ibero-americano», Jahrbuch für Geschichte Lateinamerikas, 45 (2008): 245-274.
} 
1820 representó un claro modelo de orden que favoreció al pueblo como principio positivo de legitimidad política y que estuvo inspirado por las corrientes utilitaristas de reforma social y política. ${ }^{14}$ Las asociaciones positivas del término pueblo en esta concepción no pudieron ser ignoradas. La introducción de mecanismos representativos de gobierno fue sin duda un intento de limitar las políticas turbulentas asociadas a los cabildos abiertos en los municipios, un legado del gobierno colonial, los cuales habían sido una fuente recurrente de agitación desde 1810 en adelante. ${ }^{15} \mathrm{La}$ introducción de regulaciones electorales menos excluyentes debía canalizar los conflictos políticos a formas más mediadas e institucionalizadas de gobierno. De esta manera, una de las formas preferidas de la agitación política utilizadas por grupos que excedían a las elites perdió su eficacia.

Fue de la misma forma que los gobiernos liberales de la provincia apoyaron decididamente la expansión y sistematización de la oferta educativa para el pueblo en la década de 1820 . Una consecuencia civilizadora de la escolarización debía moderar el impulso de la política moderna asociada con el proceso de independencia política. ${ }^{16}$ La misma experiencia de escolarización también debió seguir los modelos racionalizados y extendidos de orden, lo que condujo a una aceptación general del sistema lancasteriano o mutuo entre las elites como una alternativa eficaz para la educación popular. ${ }^{17}$ En estos años se vislumbró un futuro prometedor para la enseñanza elemental tanto urbana como rural. No sólo el crecimiento del sector público sustentando a las escuelas elementales,

\footnotetext{
${ }^{14}$ Marcela Ternavasio, La revolución del voto. Política y elecciones en Buenos Aires, 1810-1852 (Buenos Aires: Siglo XXI, 2002); Marcelo Caruso, «Literacy and Suffrage. The politicisation of schooling in postcolonial Hispanic America (1810-1850)». Paedagogica Historica, 46 (4), (2010): 463-478.

${ }^{15}$ Para episodios interesantes de prácticas políticas populares en el contexto de estas asambleas públicas, véase Gabriel Di Meglio, ;Viva el bajo pueblo! La plebe urbana de Buenos Aires y la política entre la Revolución de Mayo y el rosismo (Buenos Aires: Prometeo, 2006).

${ }^{16}$ Mark D. Szuchman, «In Search of Deference: Education and Civic Formation in Nineteenth-Century Buenos Aires». En Molding the Hearts and Minds. Education, Communications, and Social Change in Latin America, ed. John A. Britton (Wilmington: Scholarly Ressources, 1994), 1-18.

${ }^{17}$ Mariano Narodowski, «La expansión lancasteriana en Iberoamérica. El caso de Buenos Aires», Anuario del Instituto de Estudios Históricos y Sociales, 9 (1994): 255-278; Mariano Narodowski, «Los libros de texto de pedagogía en la formación de docentes de Buenos Aires (1810-1830)», Los manuales escolares como fuente para la historia de la educación en América Latina, eds. Gabriela Ossenbach y José Miguel Somoza (Madrid: UNED, 2001), 83-94; Newland, Buenos Aires no es Pampa; Mark D. Szuchman, "Childhood Education and Politics in Nineteenth-Century Argentina: The Case of Buenos Aires», Hispanic American Historical Review, 70 (1), (1990): 109-138.
} 
sino también la existencia de numerosas escuelas privadas, muchas de ellas estrechamente relacionadas a los círculos mercantiles de la ciudad de Buenos Aires y a los nuevos residentes protestantes, ${ }^{18}$ promovieron la alfabetización y la aritmética elemental.

La definición política de pueblo en Buenos Aires, siendo una de las expresiones más democráticas del orden político en aquel entonces, no eliminó un conflicto paralelo en la definición misma de pueblo en términos sociales, reintroduciendo, de esta manera, la estratificación social y las prácticas de distinción en este concepto. A diferencia de España, donde la decisión política de restringir el sufragio universal sobre la base de la riqueza prevaleció después de 1837, las elites porteñas no cambiaron el sufragio universal masculino ni siquiera después del régimen de Rosas (1835-1852). ${ }^{19}$ Rosas gobernó básicamente como un dictador bajo formas aún republicanas ya que era confirmado de manera rutinaria por una asamblea legislativa elegida entre los candidatos de un "partido de la unidad». Su régimen gozó de apoyo popular constante ${ }^{20}$ y Rosas celebró de un modo paternalista las virtudes del "pueblo». ${ }^{21}$ Además, muchos miembros de la población formaban el núcleo de la temida mazorca, una especie de policía secreta responsable de numerosos crímenes políticos. Por ello, algunos aspectos antiliberales de la participación política de las clases populares tuvieron lugar simultáneamente con el notorio debilitamiento de las dinámicas educativas de la década de 1820. Las restricciones económicas y una visión más conservadora de la sociedad y el progreso condujeron a una disminución de la oferta educativa pública debido a que el subsidio estatal a las escuelas fue reducido radicalmente en $1838 .^{22}$ La oposición liberal al régimen conservador-popular de Rosas ya no consideró al «pueblo» como un grupo homogéneo de ciudadanos

${ }^{18}$ Carlos Newland, «La educación primaria privada en la Ciudad de Buenos Aires (1820-1834)», Libertas, 4 (1986): 25-38.

${ }^{19}$ Sobre la historia española del concepto de «pueblo», véase el artículo «Pueblo» de Juan Francisco Fuentes en: Javier Fernández Sebastián y Juan Francisco Fuentes (eds.), Diccionario político y social del siglo XIX español. (Madrid: Alianza, 2002), 586-593.

${ }^{20}$ Oscar Chamosa, «To Honor the Ashes of Their Forebears: The Rise and Crisis of African Nations in the Post-Independence State of Buenos Aires, 1820-1860», The Americas, 59 (3), (2003): 347-378.

${ }^{21}$ Noemí Goldman y Gabriel Di Meglio, «Pueblo/Pueblos», Lenguaje y revolución. Conceptos políticos clave en el Río de la Plata, 1780-1850 (Buenos Aires: Prometeo, 2008), 131-145, 139.

${ }^{22}$ Antonino Salvadores, La instrucción primaria desde 1810 hasta la sanción de la ley 1420 (Buenos Aires: Talleres gráficos del Consejo Nacional de Educación, 1941), 209-234. 
virtuosos; los liberales comenzaron más bien a cultivar una visión diferenciada y distante de las clases populares urbanas. ${ }^{23}$ Tras el derrocamiento de Rosas, el estado institucional de las cosas no cambió significativamente y las disposiciones del derecho al sufragio permanecieron intactas hasta 1864.

El exponente más conocido de una nueva perspectiva escéptica de la equivalencia entre pueblo y virtud fue probablemente Domingo Faustino Sarmiento (1811-1888), un hombre de la provincia occidental de San Juan, quien llegó a ser un periodista muy activo e influyente y a ser electo más tarde presidente para el periodo 1868-1874. En su visionario ensayo Facundo: Civilización y Barbarie (1845), codificó la historia reciente de las provincias argentinas en los términos de una lucha entre "civilización» y «barbarie». En su consideración de las clases populares como una fuerza política de apoyo determinante a los gobiernos autocráticos, identificó el rol del pueblo en el proceso político como una fuerza bárbara. El hecho de que los gauchos apoyaran a caudillos en las provincias y que los sectores populares urbanos también respaldaran a Rosas fue visto en su obra como el impedimento principal para la imposición de un verdadero «progreso». Por ello, abogó por una política que propició la inmigración europea y una decidida urbanización, "Ciudad es sociedad», sostuvo. ${ }^{24}$ En vista de este evidente cambio de los significados del pueblo en la víspera de la era liberal posterior a 1852, fue un asunto político esencial definir qué tipo de educación "popular» deberían adoptar las elites liberales después del colapso del régimen de Rosas.

\section{LA DEMOCRACIA Y EL PUEBLO: RENUNCIA A LO «POPULAR»}

Una idea generalmente aceptada entre las elites dominantes a partir de 1852 era que un cambio de régimen político no sería posible sin un cambio demográfico. Por su parte, Sarmiento no dudó acerca del hecho de que los «Estados Sud Americanos pertenecen a una raza que figura en última línea entre los pueblos civilizados». ${ }^{25}$ Por consiguiente, destacó el

\footnotetext{
${ }^{23}$ Goldman y Di Meglio, «Pueblo/Pueblos», 140.

${ }^{24}$ Domingo Faustino Sarmiento, Educación común en el Estado de Buenos-Aires (Santiago de Chile: Imprenta de Julio Belin, 1855), 85.

${ }^{25}$ Domingo Faustino Sarmiento, De la educación popular (Santiago de Chile: Imprenta de Julio Belin i compañia, 1849), 20.
} 
hecho de que el inglés, el francés y el holandés en Norte América no estableció relación alguna con los pueblos indígenas, lo que les ayudó a establecer unidades políticas independientes, democráticas y civilizadas: ${ }^{26}$

¿Qué porvenir aguarda a Méjico, el Perú, Bolivia i otros estados sud americanos que tienen aun vivas en sus entrañas como no dijerido alimento, la razas salvajes o bárbaras indíjenas que absorvió la colonización, i que conservan obstinadamente sus tradiciones de los bosques, su odio a la civilizacion, sus idiomas primitivos, i sus hábitos de indolencia i de repugnancia desdeñosa contra el vestido, el aseo, las comodidades i los usos de la vida civilizada? ${ }^{27}$

El primer paso en la nueva senda de la pacificación y el progreso debía ser la inmigración europea. En su combinación de un liberalismo creyente del progreso con nociones racistas de civilización, particularmente, cuando observó las características de la población local, ${ }^{28}$ Sarmiento vio muchas semejanzas entre sus propuestas para la creciente población y las mejoras simultáneas en la crianza de animales. Nuevas razas de caballos y reses eran esenciales para mejorar la baja calidad del ganado local. No obstante, este proceso no era sólo un asunto de importar nuevos animales, sino más bien una cuestión de conocimiento. El «medio principal para la perfección de las razas animales» era «el libro» como un portador de observaciones pacientes hechas en el campo de la crianza en los países del norte de Europa y, en ese sentido, tan necesario como la importación de ganado. ${ }^{29}$ Inmigración y conocimiento eran, de este modo, elementos claves para la reproducción de un pueblo moderno sedentario e industrioso.

Esta visión negativa y generalizada del pueblo prevaleció entre las élites porteñas. Pero, al mismo tiempo, las decisiones fundamentales sobre la estructura política habían sido tomadas sobre la base de conside-

\footnotetext{
${ }^{26}$ Sarmiento, De la educación popular, 22.

${ }^{27}$ Sarmiento, De la educación popular, 23.

${ }^{28}$ Hay una enorme cantidad de publicaciones que discuten sobre este tema. Para una breve estimación de la postura crítica y para el impacto de las opiniones racistas culturales de Sarmiento, véase Adriana Puiggrós, Sujetos, disciplina y currículum en los orígenes del sistema educativo argentino, 1884-1916 (Buenos Aires: Galerna, 1990), 77-89.

${ }^{29}$ Puiggrós, Sujetos, disciplina y currículum, 5.
} 
rar al nuevo país como democrático. Esta constelación de problemas y suposiciones políticas resultaron, en un sentido amplio, en una amplia funcionalización política de la educación y la escolarización. Sarmiento comprendió que la revolución de los derechos políticos había llegado a las repúblicas hispanoamericanas antes de que la «inteligencia» se pudiera extender a través de las diferentes instituciones de educación popular: «I la lei no se atreve ya a poner por condición del uso del derecho que pertenece al hombre, por nada mas que ser un ser racional i libre, la capacidad en que se halla de ejercerlo prudentemente». ${ }^{30}$ En este sentido, la urgencia de educar a los futuros electores marcó el carácter político de la educación popular. Por consiguiente: «Reforma tan radical y de consecuencias benéficas no se inicia en las escuelas, sino en la opinión pública. No es el maestro sino el legislador el que ha de producirla». ${ }^{31}$ En este sentido, los significados asociados a la figura del pueblo jugaron un papel significativo en la configuración de aquello que se denominó como «educación popular». Aunque Sarmiento era muy hábil en asuntos pedagógicos, insistió en que la educación tenía que ser considerada principalmente como una labor política: «Las escuelas no se fundan con niños, sino con leyes, con rentas especiales, con la cooperacion de los padres de familia, con erogaciones espontáneas i con espíritu público que las da vida». ${ }^{32}$

Muchos otros hombres prominentes en el campo de la educación compartieron los elementos centrales de esta perspectiva. Marcos Sastre (1808-1887), un intelectual, uruguayo de nacimiento, y con experiencia en asuntos de educación, juzgaba que «la regeneración de las masas populares» era la prioridad de la época. Él creía que la «influencia del pueblo» $y$ «el poder del pueblo», siendo «una nueva influencia, la mas lejitima de todas» en la vida moderna, provenía de la propagación de la instrucción. ${ }^{33}$ Como Sarmiento, Sastre sostenía que «nada tenia que ofrecernos la España para las condiciones de la sociedad argentina debido «á nues-

\footnotetext{
${ }^{30}$ Sarmiento, De la educación popular, 18. Sobre la participación política en la ciudad durante esos años, véase la influyente obra de Hilda Sábato, The Many and the Few. Political Participation in Republican Buenos Aires (Stanford: Stanford University Press, 2001).

${ }^{31}$ Sarmiento, De la educación popular, 18.

${ }^{32}$ Sarmiento, Educación común en el Estado de Buenos Aires, 59.

${ }^{33}$ Marcos Sastre, La educación popular en Buenos Aires (Buenos Aires: Librería de Morta, 1865), 19-20.
} 
tro modo de ser democrático y á nuestras aspiraciones al progreso». ${ }^{34}$ Siguiendo el legado intelectual de su amigo liberal Estaban Echeverría (1805-1851), vio sin duda alguna el poder moralizador de la educación como función política en los nuevos regímenes modernos-democráticos y, en ese sentido, era un apasionado partidario de la «ilustracion política del pueblo» a través de los catecismos políticos que tenían que explicar conceptos como patria, libertad, igualdad, fraternidad, sufragio y representación. ${ }^{35}$ El sacerdote católico Gabriel Fuentes, un actor central en la comisión escolar local de la ciudad de Buenos Aires, expresaba ideas similares en su discurso de distribución de premios a los alumnos de escuelas de la ciudad en 1858: «La educacion de los niños —que en último resultado es la consolidacion de la sociedad por el desarrollo de la instruccion y de la civilizacion del pueblo- es tambien la piedra angular del edificio político, sobre todo en los paises democráticos». ${ }^{36}$

Frente al inmenso desafío del poder del pueblo, los Estados Unidos se habían acreditado como un modelo sobresaliente de este nuevo tipo de sociedad. Ya en su programática obra maestra De la Educación Popular (1849) Sarmiento había bosquejado un horizonte coherente para el progreso educativo en los países de América Latina basado en la adopción del modelo norteamericano de la escuela común. Él vio la ley de educación del estado de Massachusetts como «no menos importante» que la ley francesa de 1833: «Sus resultados, dada la organizacion democrática de los Estados-Unidos, son aun mas tanjibles y seguros». ${ }^{37}$ Del mismo modo, el abogado y líder intelectual Juan Bautista Alberdi (18101884) expuso la idea de crear un «yankee hispano-americano» ${ }^{38} \mathrm{y}$, en ese sentido, propuso el inglés, «idioma de la libertad, de la industria y del órden», como lenguaje superior al latín para la educación superior con

\footnotetext{
${ }^{34}$ Sastre, La educación popular en Buenos Aires, 13.

${ }^{35}$ Sastre, La educación popular en Buenos Aires, 27.

${ }^{36}$ Gabriel Fuentes y Héctor F. Varela, «Informe de la comision de educacion, correspondiente al año 1858", Memoria de la Municipalidad de la Ciudad de Buenos Aires correspondiente al año 1858, (1859), 58-63, 60.

${ }^{37}$ Sarmiento, De la educación popular, 10. Véase también Domingo Faustino Sarmiento, Comentarios de la constitucion de la Confederacion Arjentina (Santiago de Chile: Imprenta de Julio Belin I, ca.1853), 175-180.

38 Juan Bautista Alberdi, «Bases y puntos de partida para la organización política de la República Argentina», Organización de la confederación argentina, (1858), 1-172, 34, destacado en el original.
} 
el fin de aprender de la acción civilizadora de la «raza» anglosajona. ${ }^{39}$ Sarmiento también tenía una alta apreciación del idioma inglés, el cual era «el primero en las ciencias de la educacion i el rival del frances en filosofía, literatura i actividad intelectual». ${ }^{40}$ Pero la consolidación de una identidad nacional de grupos heterogéneos de inmigrantes requería, en su opinión, la consolidación de un idioma español común y reformado. Estas impresiones positivas y apasionadas acerca de los Estados Unidos eran incluso más explicitas en el caso de Juana Manso (1819-1875), una escritora, activista, precursora de los derechos de las mujeres y directora de la primera escuela primaria experimental para ambos sexos en la ciudad de Buenos Aires, quien a veces fue considerada como una especie de «Sarmiento con faldas». Manso estaba convencida de la superioridad de las culturas protestantes. Un signo elocuente de las tensiones de la época fue el episodio en el que Manso, en una de sus conferencias sobre protestantismo en mayo de 1866, sostenida en la Escuela Modelo en Catedral al Norte, se enfrentó a una oposición feroz de grupos católicos, quienes interrumpieron la sesión con injurias y le arrojaron polvos pestilentes a su ropa. ${ }^{41}$

Un caso de transición interesante entre el casi inalcanzable modelo norteamericano y las decepcionantes realidades locales fue el novedoso estado federal de California, que había sido anexado a Estados Unidos en 1846. Alberdi, un intelectual que abogaba por un realismo imbuido en el espíritu de empresa e invención, vio en el caso de California el paso cuasi milagroso de las formas de gobiernos tradicionales, ineficientes y católicas — que él asociaba con la administración mexicana del territorio- al promisorio desarrollo de su integración a los Estados Unidos. Admiraba la nueva constitución de California de 1849. Un punto decisivo para él fue el establecimiento de un fondo estatal permanente para las escuelas primarias, ya que la única solución que él consideraba razonable para las naciones hispanoamericanas debía ser la educación como garante del pacto político. ${ }^{42}$ Sarmiento también vio en la anexión de California a los Estados Unidos un proceso de civilización de una población posco-

\footnotetext{
${ }^{39}$ Alberdi, «Bases y puntos de partida», 34.

${ }^{40}$ Sarmiento, Educación común en el Estado de Buenos Aires, 77.

${ }^{41}$ Lidia F. Lewcowicz, Juana Paula Manso (1819-1875). Una mujer del siglo XXI (Buenos Aires: Corregidor, 2000), 167.

${ }^{42}$ Alberdi, «Bases y puntos de partida», 28.
} 
lonial retrasada, semejante a sus proyectos para los países de la América hispana. Era un tanto «alentador» ver cómo el «carácter de Norte América» había prevalecido sobre el legado de la España colonial y la administración mexicana. ${ }^{43} \mathrm{Su}$ punto de vista fue también confirmado por viajeros extranjeros, como el político y escritor chileno Benjamín Vicuña Mackenna (1831-1886), quien comparó San Francisco con Buenos Aires debido a los altos salarios y a la actividad general de la población. ${ }^{44}$

La historiografía de la educación argentina ha señalado las dificultades relacionadas con esta pretendida transformación, principalmente al analizar las soluciones contrarias ofrecidas por Sarmiento y Alberdi en el campo de la educación. ${ }^{45}$ Acorde con el discurso progresista de la época, ambos destacaron la relevancia de la educación para cambiar la población. En general, la idea de que el pueblo realmente existente era incapaz de vivir bajo condiciones democráticas, era muy popular entre las elites. Sarmiento y Alberdi fueron muy efectivos en la activación de estos significados. Pero sus concepciones de educación enunciadas en sus escritos eran bastante diferentes. Sarmiento propugnó por una sociedad completamente distinta a la educada bajo el régimen colonial, las guerras de independencia y el despoblamiento y, por consiguiente, defendió un "vasto sistema de educacion». ${ }^{46}$ Sarmiento, quien había escrito informes decisivos acerca el progreso educativo en Europa y los Estados Unidos y quien había dirigido la primera escuela normal de maestros de Sudamérica durante su exilio en Santiago de Chile, tuvo una visión muy amplia del proceso de educación y evocó siempre los logros de los Estados Unidos como su modelo preferido de progreso. Para él, los estados de Norte América eran un tipo de sistema de gobierno dedicado a una concepción amplia de educación popular que abarcaba los asilos, el sistema escolar,

\footnotetext{
${ }^{43}$ Sarmiento, Educación común en el Estado de Buenos Aires, 79.

${ }^{44}$ Citado en María Sáenz Quesada, El estado rebelde. Buenos Aires entre 1850-1860 (Buenos Aires: Editorial de Belgrano, 1982), 209.

${ }^{45}$ Para una discusión general sobre los proyectos de Alberdi y Sarmiento referidos al nuevo periodo después de Rosas, véase, entre otros, a Tulio Halperín Donghi, Una nación para el desierto argentino (Buenos Aires: CEAL, 1992), 37-55; Marta Bonaudo, «Los grupos dominantes entre la legitimidad y el control», Liberalismo, estado y orden burgués (1852-1880), (1999), 27-96, particularmente 31-35. Sobre la «victoria» de la posición de Alberdi en el largo plazo: Alberto Lettieri, «De la „República de la Opinión“ a la „República de las Instituciones“», Liberalismo, estado y orden burgués (1852-1880), (1999), 97-160.

${ }^{46}$ Sarmiento, «El editor», Anales de la educación común, 1 (1), (1858): 1-6, 1.
} 
y las conferencias para el público adulto. ${ }^{47}$ Pero su prioridad política en la ciudad de Buenos Aires fue evidentemente el establecimiento de un sistema escolar para el pueblo.

Alberdi no fue menos severo que Sarmiento en su opinión sobre las clases populares argentinas. Estaba convencido del hecho que «sin nueva población es imposible el nuevo régimen». ${ }^{48} \mathrm{En}$ su tarea de mejorar el gobierno a través del mejoramiento de los gobernados, prefirió «la educación que se opera por la acción espontánea de las cosas» a la mera «instrucción» en las escuelas. ${ }^{49}$ No rechazó las escuelas primarias como instituciones centrales para la educación del pueblo; sin embargo, las políticas escolares por sí solas no podrían contrarrestar los efectos primitivos de la escasa población del extenso territorio, los modos incultos y la falta de hábitos de trabajo. La inmigración y el progreso material tendrían efectos positivos sobre la educación del pueblo, afirmaba, y, por ello, la prioridad debería ser la promoción de la inmigración, la modernización del trabajo y la multiplicación de la riqueza. Sarmiento replicaba: «Pero el emigrante del mediodia de Europa nos trae por lo jeneral brazos robustos, mayor actividad para adquirir, i no pocas veces igual destitucion de educacion que aquella de que adolecemos». ${ }^{50}$ Más allá de estas posiciones controvertidas, las élites de Buenos Aires optaron rápidamente por la idea de Sarmiento sobre la extensión de la enseñanza elemental en el campo de la educación, más allá de la activa política de promoción de la inmigración europea.

Los planes de Sarmiento, Sastre y Manso para la educación popular pusieron énfasis en la escolarización de los niños de los pobres como algo esencial para la tarea de estabilizar el nuevo orden. Siguiendo su obra precursora, construida sobre la oposición de la ciudad civilizada contra el «desierto» salvaje, Sarmiento vio en los suburbios de las ciudades el primer objetivo de acción educativa urgente. Se refirió a este espacio transitorio entre las ciudades y el campo como algo particularmente peligroso, porque «la menor conmocion de la república» podría conducir

\footnotetext{
${ }^{47}$ Sarmiento, De la educación popular, 16-18.

${ }^{48}$ Alberdi, «Bases y puntos de partida», 142.

${ }^{49}$ Alberdi, «Bases y puntos de partida», 32.

${ }^{50}$ Domingo Faustino Sarmiento, Las escuelas: base de la prosperidad i de la república en los Estados Unidos (Nueva York: s.d., 1865), 48.
} 
«a vomitar hordas de vandalos». ${ }^{51}$ Por su parte, Alberdi se abstuvo de hacer la simple oposición entre la población urbana y rural que resultaba del diagnóstico pesimista de Sarmiento acerca de la realidad argentina: "Rosas no ha dominado con gauchos sino con la ciudad. Los principales unitarios fueron hombres del campo [...]. La mazhorca (sic) no se componía de gauchos». ${ }^{52}$

En el esfuerzo de hacer de la Provincia de Buenos Aires, y sobre todo de su orgullosa ciudad capital, una especie de versión austral de California, los puntos de vista coincidentes acerca de la población inculta y los pobres amenazantes, así como la simultánea aceptación generalizada de un "gobierno para el pueblo» relacionado con la democracia y la civilización entre las élites liberales se disolvieron en diferentes ámbitos de acción. En el campo de los discursos y la acción abierta por estas actitudes ambivalentes hacia el pueblo, diferentes grupos en la escena educativa local dieron impulso a énfasis divergentes en la modernización y expansión de la educación.

\section{LO «POPULAR» EN LA POLÍTICA ESCOLAR: ESTRATEGIAS DIVERGENTES}

Amén de esta visión hegemónica sobre el pueblo, la política educativa en la ciudad de Buenos Aires, foco del siguiente análisis, fue particularmente conflictiva y fluctuante después de 1852. Por un lado, instituciones y actores legítimos yuxtapuestos, sobre todo la Sociedad de Beneficencia y la Universidad de Buenos Aires, se enfrentaron por el control de la regulación educativa. Los escasos efectos de estas instituciones heredadas abrieron un amplio campo de intervención a nuevos actores. Pero, por otro lado, proyectos diferentes de desarrollo educativo estaban en juego, y estos proyectos también incluían significados divergentes de "pueblo» y lo «popular».

El programa de gobernabilidad educacional de Sarmiento era claramente político-educacional. Su permanencia entre 1856 y 1860 en el cargo de director del Departamento de Escuelas de la Provincia de Buenos Aires puso de manifiesto un campo de experimentación acerca de sus

${ }^{51}$ Sarmiento, De la educación popular, 36.

${ }^{52}$ Alberdi, «Bases y puntos de partida», 37-38, destacado en el original. 
ideas de participación popular en el suministro de educación como una experiencia de educación cívica, algo que él vinculaba a las formas norteamericanas de gestión local de la escuela. ${ }^{53}$ No sólo los efectos de la escolarización serían beneficiosos para la consolidación del orden democrático, sino el mismo proceso de organizar y proveer la educación elemental del pueblo podría ser considerado en sí mismo como un proceso educativo para la parte «decente» de la población interesada en el avance de este sector. Este era un camino alentador, porque

no existen clases sociales opuestas en Buenos Aires, como en otras partes de Sud América; no existe un concepto heredado de nobleza o jerarquia social o una profunda diferencia entre el pueblo y la clase alta porque la riqueza se alcanza fácilmente y la instruccion puede ser encontrada en el pobre inmigrante tanto como en el estudiante de nuestras universidades. ${ }^{54}$

En su opinión, Buenos Aires era un campo apropiado para este nuevo tipo de experiencia debido a su condición de ciudad puerto, la relativamente alta tasa de alfabetismo y la composición específica de su población local, la que incluía un «blanqueamiento» gradual de los habitantes de la ciudad debido a una constante reducción de la población indígena y negra. ${ }^{55}$ Celebró que sólo en Buenos Aires, y no como fue el caso de otras capitales más grandes, como por ejemplo, Río de Janeiro o Lima, el gobierno local invertía una cantidad considerable de dinero en escuelas. Es más, sólo en los barrios de Buenos Aires algunos grupos de ciudadanos se hicieron a la tarea de fundar «monumentales escuelas». ${ }^{56}$ Buenos Aires era la única ciudad en Sudamérica donde las tasas de alfabetización de las mujeres eran incluso más altas que la de los hombres, una excepción bastante notable en la senda «normal» del desarrollo

${ }^{53}$ Sobre la caracterización y carencias de su actividad en el Departamento de Escuelas, véase el diagnostico muy completo de Ángela Inés Oría, «Desafíos a la "educación popular". Sarmiento en el Departamento de Escuelas, 1856-1862», Tesis de Maestría, Universidad de San Andrés, 2004.

${ }^{54}$ Segundo informe del Gefe del Departamento de Escuelas del Estado de Buenos Ayres por el año de 1858 (Buenos Aires: Imprenta Argentina, 1859), 52.

${ }^{55}$ Sáenz Quesada, El estado rebelde, 197-201. No obstante, vestigios de una realidad más multirracial del Buenos Aires colonial eran aún visibles. Por ejemplo, la Sociedad de Beneficencia fundó después de 1852 una escuela para «niñas de color». Ramos, Historia de la instrucción primaria, 9.

${ }^{56}$ Segundo informe, 4. 
educativo del siglo XIX. ${ }^{57}$ Optimista, comentó después de haber llegado a la ciudad de Buenos Aires que «tiene aqui elementos para una completa regeneracion.» ${ }^{58} \mathrm{Su}$ visión integradora de las políticas escolares, que incluía a todas las clases sociales, era ampliamente aceptada entre las elites. Por ejemplo, la comisión escolar local definió «la educacion comun y la escuela comun» como "aquellas que los vecinos de una parroquia mantienen en comun para educar en comun a sus hijos». ${ }^{59}$ Como un modo de anticiparse a la vida social, las escuelas deberían preparar «ese sentimiento de simpatía a adhesion entre sus miembros» de tal forma de contrarrestar «las antipatias de clase». ${ }^{60}$ En otras palabras: «La Escuela Parroquial asi entendida, no es la actual escuela abierta á los menesterosos y desdeñada por los favorecidos de la fortuna». ${ }^{61}$ En resumen, la ciudad de Buenos Aires, desde una perspectiva política y racial, no reflejaba del todo a Argentina y, en ese sentido, el proyecto democrático y «civilizador» sarmientino de participación popular en la organización de la oferta educativa no parecía ser completamente ilusorio.

Sarmiento veía en todas partes señales alentadoras de participación popular. En la ciudad de Buenos Aires, «las parroquias se han reunido espontáneamente para votar por suscripcion los fondos necesarios para el sosten de sus escuelas». ${ }^{62}$ Ciudadanos notables del barrio norte de la Catedral escribieron directamente a Sarmiento y expusieron sus objetivos y estrategias: El establecimiento de una escuela primaria superior, pensada para que niños adquieran el dominio de la lectura, escritura, y aritmética, y la exigencia de una suscripción mínima para su funcionamiento. ${ }^{63}$ Sarmiento aprobó esta iniciativa, en la que 85 personas, entre

\footnotetext{
${ }^{57}$ Sarmiento, De la educación popular, 130.

${ }^{58}$ Citado en: Sáenz Quesada, El estado rebelde, 192.

${ }^{59}$ Informe anual de la Comisión de Educación de la Municipalidad de la Ciudad de Buenos Aires (Buenos Aires: Imprenta de La Revista, 1857), 10.

${ }^{60}$ Informe anual de la Comisión de Educación de la Municipalidad de la Ciudad de Buenos Aires, 10.

${ }^{61}$ Informe anual de la Comisión de Educación de la Municipalidad de la Ciudad de Buenos Aires, 10.

${ }^{62}$ Sarmiento, Educación común en el Estado de Buenos Aires, 81. Sarmiento mantenía evidentemente sólidos lazos políticos con estos vecinos ilustres y pudientes organizados. Véase la comunicación sobre los resultados de las elecciones en la Parroquia de Catedral al Norte enviada a Sarmiento, 6 de marzo de 1858. Museo Histórico Sarmiento - Archivo Histórico, N. ${ }^{\circ} 4388$.

${ }^{63}$ Carta de Felipe Lavallol y otros a Sarmiento, 2 de Septiembre de 1858, Fundación de escuelas públicas en la Provincia de Buenos Aires durante el gobierno escolar de Sarmiento (1856-1861; 18751881), (1939), 79-80.
} 
ellas nueve mujeres, contribuyeron con dinero para el establecimiento de la nueva escuela. ${ }^{64}$ Consideró este episodio como una «exploracion en la opinion publica» sobre la conveniencia de exigir un impuesto para educación. ${ }^{65}$ Sarmiento también patrocinó una iniciativa similar en el barrio sur de la Catedral, donde 78 ciudadanos hicieron inicialmente contribuciones financieras considerables para otra nueva escuela modelo. ${ }^{66} \mathrm{In}$ cluso grupos "populares» parecen haber sido también parte del creciente interés en el progreso educativo: La creación de una escuela primaria en el barrio obrero de La Boca fue también el resultado de una petición organizada por muchos ciudadanos, ${ }^{67}$ un acontecimiento interesante si se considera la cierta reticencia que tenían algunos inmigrantes de enviar a sus niños a la escuela. ${ }^{68}$ Más allá de estos acontecimientos destacados, los elementos de participación popular en la concepción de Sarmiento eran bastante limitados, porque este proceso coincidía, con lo que él ya había visualizado: la entrada en escena de un nuevo burócrata educacional y la fuerza dominante del Estado conduciendo el desarrollo del sistema escolar. ${ }^{69}$

La política escolar se convirtió en un espacio de reconstrucción de la sociedad que excedió ampliamente el campo específico de la pedagogía y las escuelas. En su visión de la educación como una arena de contienda político-educacional, no resulta inesperado que Sarmiento organizara una ceremonia pública en 1860 para la inauguración de una de las es-

\footnotetext{
${ }^{64}$ La lista de los donantes fue publicada, Segundo informe, 48-50.

${ }^{65}$ Segundo informe, 45. Evidentemente, Sarmiento no era tan ingenuo. No esperó hasta que surgieran demandas locales de escolarización, como ocurrió en algunas ciudades y municipios de la provincia. De manera altanera, después de la victoria de las tropas de Buenos Aires contra las otras provincias de la Confederación Argentina, afirmó haber convencido al gobernador de la provincia acerca de invertir algunos millones en las nuevas escuelas primarias: «Si las ciudades no piden escuelas, derramárelas en las campañas, y haré desaparecer en seis años el guacho y el compadrito». Véase el discurso de Sarmiento, celebrado en la ciudad de San Juan, 22 de junio de 1869, impreso en: Fundación de escuelas públicas, 93-94.

${ }^{66}$ Segundo informe, 50-52. Véase también: Domingo Sarmiento, Informe del comisionado especial para la creacion de una escuela modelo decretada por la Municipalidad de la Ciudad de Buenos Aires (Buenos Aires: Imprenta Argentina, 1857).

${ }^{67}$ Véase el decreto del gobernador Valentín Alsina que respalda la escuela, 15 de abril de 1856, publicado en: Fundación de escuelas públicas, 2-3.

${ }^{68}$ Tercer informe del gefe del Departamento de Escuelas de la Provincia de Buenos Aires por el año de 1860 (Buenos Aires: Imprenta Arjentina de El Nacional, 1861), 70-71.

${ }^{69}$ Para un análisis exhaustivo del modelo de gestión de Sarmiento, véase Oría, «Desafíos a la "educación popular"», 101-104.
} 
cuelas modelo antes mencionada, la de Catedral al Norte, en donde enemigos políticos acérrimos, el Presidente Santiago Derqui (1800-1867), el presidente anterior Justo José de Urquiza (1801-1870) y el gobernador de la provincia de Buenos Aires y futuro presidente del país, Bartolomé Mitré (1821-1906), un oponente reciente de Urquiza en los campos de batalla, se reunieron. ${ }^{70}$ Esta ceremonia pública tal vez sea la primera reunión masiva en la ciudad enfocada en el tema de las escuelas y la educación, reveló el ascenso de la masonería liberal en la política de la época. ${ }^{71}$ Los grupos a favor del establecimiento de la nueva escolarización permanecieron estrechamente relacionados a esta red de asociación y participación política de tendencia liberal. ${ }^{72}$

La limitada pero alentadora participación popular en el apoyo y la inspección de las nuevas escuelas impresionó no solo a Sarmiento, sino también a otras autoridades educativas. En 1857, la comisión escolar local veía el espíritu público actuando en las juntas escolares locales, listas para apoyar los esfuerzos relativos a la mejora de las escuelas. ${ }^{73}$ Un año más tarde, la comisión declaraba «el espiritu público empieza á interesarse directamente en esta cuestion social; y bien considerando todo, puede deducirse que estamos en camino de progreso». ${ }^{74}$ También destacaba que muchos ciudadanos (vecinos) de los diferentes barrios ayudaron en la organización y control de las escuelas locales. De hecho,

\footnotetext{
${ }^{70}$ Véase el momento de la implementación de la escuela en «Acta de inauguración de la escuela superior de la Catedral al Norte», Fundación de escuelas públicas, 87-88.

${ }^{71}$ La expansión de la masonería después de 1853 fue sorprendente. En pocos años se establecieron numerosas logias y éstas se volvieron factores cruciales en la conformación de la nueva vida política debido a los altos cargos ocupados por muchos de sus miembros. Pilar González Bernaldo de Quirós, Civilidad y política en los orígenes de la Nación Argentina. Las sociabilidades en Buenos Aires, 18291862 (Buenos Aires: FCE, 2000), 234-244.

${ }^{72}$ Con motivo de la inauguración de la escuela, Sarmiento se propuso reconciliar estos antagonismos políticos, al reunirlos en la logia Unión del Plata. Su discurso en la inauguración de la escuela, evocando todas las ideas conocidas de modernidad, republicanismo y progreso, pudo ser entendido como una declaración polisémica referida tanto al movimiento educacional como a la política en general: el encuentro solemne «inaugura una época nueva en nuestros fastos morales, intelectuales, políticos y comerciales». Sarmiento, «Discurso del señor Sarmiento», Fundación de escuelas públicas, 84-87, aquí 85. Tres días después de la ceremonia, todos los asistentes antes mencionados eran promovidos al grado más alto que otorgaba la logia. Gustavo A. Brandariz, «La actividad masónica en la educación argentina (1810-1910)», Temas de patrimonio cultural, 2004, 33-51, 43-44.

${ }^{73}$ Informe anual de la Comisión de Educación, 16.

${ }^{74}$ Informe anual de la Comisión de Educación de la Municipalidad de la Ciudad de Buenos Aires (Buenos Aires: Imprenta de El Orden, 1858), XIII.
} 
los miembros de las juntas escolares locales fueron los principales recolectores de información para la comisión local de educación y sus -a menudo, negativos - comentarios sobre la calidad de las escuelas formaban parte de un modelo de integración de participación "popular» en el gobierno del sistema escolar emergente. ${ }^{75}$ El Inspector General de Escuelas, el filósofo, masón y exministro de Relaciones Exteriores, Luis José de la Peña (1796-1871), ${ }^{76}$ afirmó en 1865 que los consejos escolares locales "han abrazado con entusiasmo la tarea de aumentar el numero de niños que concurren a las escuelas» ${ }^{77}$ y repitió la consigna: «la educacion del pueblo tiene que ser llevada a cabo por el pueblo». ${ }^{78}$

Pero no todos los actores relevantes del campo educacional compartían este punto de vista sobre el papel del pueblo en la política educativa. Marcos Sastre, un exitoso autor de textos escolares ${ }^{79}$ y con una presencia sorprendentemente menor en la historiografía de la educación argentina, ${ }^{80}$ era muy cauteloso sobre el papel del pueblo en el desarrollo de las políticas escolares. La inspiración (norte)americana de los proyectos de Sarmiento para la reforma educativa no era para él la panacea. Sastre sostenía un punto de vista más pesimista sobre las posibilidades del pueblo en la expansión de la escolarización. A diferencia del espíritu de asociación exhibido en la vida social norteamericana, «buscar el apoyo directo de la ignorancia para producir la ciencia, es caer en un círculo vicioso». Esto es solo una «una exitacion facticia (sic), momentánea, debida à la persuasiva del Sr. Sarmiento». ${ }^{81}$ Esta situación poco auspiciosa era inevitable debido a «la misma falta de ilustracion general» que «hace

\footnotetext{
${ }^{75}$ Véanse los diferentes informes de los consejos escolares locales del año 1858 en Informe anual de la Comisión de Educación de la Municipalidad de la Ciudad de Buenos Aires.

${ }^{76}$ Clara Alicia Jalif de Betranou, «Luis José de la Peña, primer profesor de filosofía de la Universidad de Montevideo: sus lecciones de filosofía (1827)», Cuadernos americanos, 3 (105), (2004): 138-144.

${ }^{77}$ Informe del Departamento de Escuelas al gobierno de la Provincia de Buenos Aires. En el mes marzo de 1866 (Buenos Aires: Imp, Lit. y fundición de tipos à vapor de Bernheim, 1866), 9.

${ }^{78}$ Informe del Departamento de Escuelas al gobierno de la Provincia de Buenos Aires. En el mes marzo de $1866,10$.

${ }^{79}$ Marcos Sastre, Lecciones de arismética para las escuelas primarias de niños y niñas. (Buenos Aires: Librería de Ortíz, 1854); Marcos Sastre, Lecciones de gramática para la enseñanza primaria de niñas y niños (Buenos Aires: Librería de Pablo Morta, 1859).

${ }^{80}$ Excepción: Newland, Buenos Aires no es Pampa, 173-174.

${ }^{81}$ Marcos Sastre, «Bibliografía» posdata de Luis L. Dominguez (ed.), Escritos politicos, economicos y literarios, del doctor D. Florencio Varela (Buenos Aires: Imprenta de El Orden, 1859), 313-318, 315.
} 
que ese pueblo á quien apostrofa no vea el precipicio ni crea en él». ${ }^{82} \mathrm{El}$ «realismo» de Sastre era apoyado por algunos actores que abogaban por las antiguas nociones del "paternalismo liberal». Estos actores habían promovido el argumento de que la falta consistente de educación en el pasado habría conducido a la imposibilidad de la participación popular en las políticas escolares de ese entonces. ${ }^{83}$

El punto de vista particularmente realista de Sastre sobre el pueblo, y su trayectoria como un reformador educacional católico y liberal, lo condujeron a apoyar un enfoque diferenciado de la política educativa de Sarmiento. Por ejemplo, se negó culpar a los padres de los niños pobres que no asistían a las escuelas gratuitas. Por el contrario, enfatizó más bien los problemas relacionados a la configuración de la oferta escolar y estuvo en contra de las regulaciones conducentes a la educación obligatoria: ${ }^{84}$ "Cuando la escuela se ha establecido con un buen preceptor, la asistencia ha sido satisfactoria», destacaba. ${ }^{85}$ En este sentido, y en conflicto con las prioridades político-educacionales de Sarmiento, formuló un programa de política escolar más pedagógico-educacional, al insistir en el rol del profesor y la reforma pedagógica.

Incluso entre los círculos liberales más entusiastas, las posiciones de Sarmiento no prevalecieron por completo. Su amiga y cooperadora Juana Manso, una escritora talentosa y una de las editoras de la primera revista educacional argentina, los Anales de la Educación Común, no estuvo probablemente tan entusiasmada con el alcance de los grupos que constituyen el «pueblo». Sus propuestas de reforma educacional mostraban un esfuerzo real de cortar de manera más radical con la cultura y costumbres existentes que el que incluso Sarmiento se había imaginado. Estaba convencida del hecho de «el hombre ya educado no puede ser temperado después de haber crecido ignorante». ${ }^{86}$ Sin una estrategia sólida de reeducación de las nuevas generaciones, advertía, «nunca habrá en este país orden. El pueblo será siempre una fuerza bruta, cuyo brazo estará seguramente a la orden

\footnotetext{
82 Sastre, «Bibliografía», 314-315.

${ }^{83}$ Manuel R. García, "Advertencia», prólogo a: Principios de gobierno para el uso de las escuelas del Estado de Buenos Aires, (1860): 3-4, 4.

${ }^{84}$ Sastre, La educación popular, 6.

${ }^{85}$ Sastre, La educación popular, 7.

${ }^{86}$ Juana Manso, «Organización de las escuelas», Album de señoritas, I (1854): 9-11, 10.
} 
del primer caudillo que lo quiera armar» ${ }^{87} \mathrm{~A}$ pesar de sus negativos puntos de vista generales acerca del pueblo, compartía la perspectiva optimista y educativa preponderante de la época: «Cuál es la diferencia entre una gran nación pasada y una nueva gran nacion? La educacion popular». ${ }^{88}$

Juana Manso había sido designada directora de la primera escuela primaria para ambos sexos de la ciudad de Buenos Aires en 1859, lo que significaba un gran desafío al monopolio de la educación femenina a cargo de la Sociedad de Beneficencia. ${ }^{89}$ Ella estaba radicalmente en contra de las prácticas educacionales existentes y desconfiaba de casi todos los maestros en actividad. Su rechazo a la sociedad heredada culminó en su propuesta de educar a todos los niños y niñas en hogares escolares. «La principial e inmediata ventaja de estas escuelas es la de separar a los niños de cualquier otra influencia que la instruccion a la que están sujetos»..$^{90}$ Estas escuelas tenían que educar a las mujeres hasta la edad de 18 años y a los hombres hasta los 21. Su voluntad de dejar atrás el legado cultural colonial español era tenaz. Cuando discutió acerca de la falta de buenos textos escolares en español, propuso «que el idioma inglés sea declarado materia de enseñanza primaria». ${ }^{91}$ Ella propuso razones prácticas, como los costos de la traducción y la publicación de varios textos escolares necesarios tanto ingleses como norteamericanos. Su argumento a favor de obras escolares en un inglés amigable, no fue de ningún modo casual. No sólo tradujo al castellano el plan para las escuelas de enseñanza primaria graduadas urbanas de Chicago y apoyó decididamente todas las propuestas de consolidación de las escuelas primarias norteamericanas como un modelo viable de cambio educacional, sino que, además, se sintió muy decepcionada por el curso de los acontecimientos en las repúblicas de América Latina. Su identificación con los Estados Unidos fue casi ilimitada. Tan fuerte era su admiración por los modelos norteamericanos de organización social que también recomendó el uso de un libro de texto sobre la historia de los Es-

\footnotetext{
${ }^{87}$ Juana Manso, «Educación popular», Álbum de señoritas, I (1854): 26-27, 26.

${ }^{88}$ Manso, «Educación popular».

${ }^{89}$ Solicitud de Sarmiento a la presidenta de la Sociedad de Beneficencia, 15 de abril de 1859, publicado en Fundación de escuelas públicas, 57-59.

${ }^{90}$ Manso, «Educación popular», 17.

${ }^{91}$ Carta de Manso a Sarmiento, 20 de febrero de 1868, publicada en Anales de la educación común, V (1868): 216-220, 218.
} 
tados Unidos para el último grado de las escuelas primarias argentinas ${ }^{92}$. En este caso, la historia de los Estados Unidos estaba en segundo lugar, solo después de la historia de Argentina, sobre la cual había escrito uno de los primeros textos escolares. ${ }^{93}$ También admiraba a su hija que «detesta la gasmoñería» $\mathrm{y}$ "tiene el espíritu yankee» ${ }^{94}$ y soñaba con ser una mujer (norte)americana. En una completa desaprobación de las asociaciones civiles relacionadas con la educación, como la Sociedad de Beneficencia, ella vio su misión «redimiendo la personalidad intelectual de la mujer de las torpes tradiciones orientales que nos lego la conquista». ${ }^{95}$

El enfoque más político de escolarización mostrado en las actividades de Sarmiento y el enfoque más cauteloso y más centrado en la pedagogía de Sastre incluyeron diferentes significados del pueblo y de la organización popular. Por supuesto, proyectos radicales, tales como los de una extensa y consecuente norteamericanización defendidos por Juana Manso, no estaban en el centro de la escena educacional. En los numerosos conflictos educacionales que tuvieron lugar en las décadas de 1850 y 1860 , Manso apoyó normalmente a Sarmiento. Estas divergencias en el ámbito de las políticas escolares, basadas en diversas concepciones acerca de las posibilidades y límites del pueblo, afectarían el camino bastante inestable del desarrollo educativo durante estos años.

\section{POLÍTICAS ESCOLARES CONFLICTIVAS PARA EL «PUEBLO»}

Como ya se mencionó, los primeros pasos hacia un renovado sistema de educación popular continuaron las líneas políticas fundamentales de la época de oro del liberalismo de 1820. El restablecimiento de la Sociedad de Beneficencia para la organización y la inspección de las escuelas de mujeres y los poderes de superintendencia sobre la educación primaria de varones otorgados a la Universidad de Buenos Aires, ambos lega-

\footnotetext{
92 Juana Manso, «A los maestros», prólogo al Curso graduado de instrucción en las escuelas públicas de Chicago. Para servir de modelo á las de la República Argentina (1869): 3-12, 5.

${ }^{93}$ Juana Manso, Compendio de la historia de las Provincias Unidas del Rio de la Plata (Buenos Aires: Estrada, 1863).

${ }^{94}$ Carta de Manso a Sarmiento, 5 de febrero de1868, Anales de la educación común, V (1868): 232237, 234.

${ }^{95}$ Carta de Manso a Sarmiento, 5 de febrero de1868, 235. Véase también su clara predilección por las escuelas norteamericanas en su carta a Sarmiento del 27 de abril de 1863. Museo Histórico Sarmiento - Archivo Histórico, N. ${ }^{\circ} 7426$.
} 
dos de las viejas políticas liberales, fueron solamente complementados con la creación de una escuela normal para la formación de maestros en 1852. Esta escuela normal, con un programa de estudios sofisticado distribuido en cinco años de asistencia, estuvo inspirada en el modelo de la escuela normal francesa de Versalles, la cual Sarmiento había descrito en su libro De la educación popular. ${ }^{96}$ También fue nombrado un inspector general de escuelas, el educador protestante alemán German Frers. ${ }^{97}$

Después de estos primeros impulsos, las políticas escolares oscilaron de manera evidente. La estructura dual del gobierno educacional, repartida entre la Sociedad de Beneficencia y la Universidad, complicó en el transcurso del tiempo el funcionamiento de las políticas escolares. Además, debido a la nueva ley de municipalidades, la ciudad de Buenos Aires tuvo que supervisar a las escuelas de la ciudad desde 1854 en adelante, agregando una instancia más al complicado gobierno de las escuelas. Sarmiento, en sus primeros pasos en la política local, colaboró con la ciudad y fue un miembro activo de su comisión escolar local. ${ }^{98}$ Para agregar un elemento más a la confusión de competencias, el gobierno provincial, por su parte, creó un Consejo de Instrucción Pública el 28 de febrero de 1855, presidido por el rector de la universidad. ${ }^{99}$ Este nuevo consejo no funcionó en la práctica. Algunos meses más tarde, un nuevo Departamento de Escuelas de la Provincia de Buenos Aires se ponía en funcionamiento y el mismo Sarmiento fue nombrado su director. ${ }^{100}$

Sarmiento, considerado ya un político muy influyente, tendió a concentrar todos los poderes educacionales en sus manos. Entre sus primeras actividades oficiales, clausuró la escuela normal de varones, establecida tan solo en 1856, la cual Sarmiento consideraba superficial y costosa. ${ }^{101}$ Claramente se trataba de una reacción, porque él había perdido a uno de sus más admirados activistas educacionales de «base», al Inspector General Frers en 1855. Como protestante, Frers había enfrentado una

\footnotetext{
${ }^{96}$ Salvadores, Instrucción primaria, 255-256. Un sucinto análisis de estos sucesos puede encontrarse en José Bustamente Vismara, "Entre el decir y el hacer. Sarmiento, los municipios y la administración de las escuelas», Estudios de Teoria Literaria, 1 (1), (2012): 27-34.

${ }^{97}$ Ramos, Historia de la instrucción primaria, 4.

98 Newland, Buenos Aires no es Pampa, 160.

${ }^{99}$ Véase el decreto en Registro oficial del gobierno de Buenos-Aires, vol. 34 (1856), 32-33.

${ }^{100}$ Registro oficial del gobierno de Buenos-Aires, vol. 35. (1856): 56.

${ }^{101}$ Newland, Buenos Aires no es Pampa, 160.
} 
tenaz oposición católica, lo que finalmente terminó por costarle el cargo de inspector escolar. Poco tiempo después, fue nombrado director de la escuela normal femenina, creada por la Sociedad de Beneficencia en 1855. ${ }^{102}$ Sarmiento también intentó extender sus poderes en perjuicio de esta sociedad. Sus ataques contra el singular rol que jugó la Sociedad de Beneficencia están bien documentados. Abogó por la integración de las escuelas femeninas en las nuevas estructuras de gestión educacional, presididas por él mismo. Asimismo, consideró también la instalación de la comisión escolar local en la ciudad de Buenos Aires como no propicia para las reformas educacionales. Por su parte, la comisión se quejó por los conflictos reiterados sobre competencias y caracterizó la Dirección General de Escuelas bajo la supervisión de Sarmiento como «sin atribuciones definidas por la ley». ${ }^{103}$ Estos episodios de conflicto abierto entre el Departamento de Escuelas y la comisión escolar local, encabezadas respectivamente por Sarmiento y el sacerdote Gabriel Fuentes, cesaron recién en 1860, cuando el consejo de la ciudad delegó el control sobre las escuelas de la ciudad al Departamento de Escuelas, debido a que Fuentes, la persona importante en la comisión escolar local, había sido elegido para el congreso provincial. ${ }^{104}$

Entretanto, Sarmiento estaba tan fuertemente involucrado en política nacional que no siempre fue capaz de ejercer su función diligentemente. $\mathrm{Al}$ igual que en el caso de Fuentes, cuya elección en la asamblea legislativa determinó la disolución de la comisión escolar local, el puesto ocupado por Sarmiento fue también ad personam. En 1861, cuando Sarmiento no estaba disponible para la gestión educacional, el Departamento de Escuelas de la provincia de Buenos Aires fue traspasado a la universidad. Aunque Sarmiento lamentó la situación — «habría sido mejor dárselo a la policía. Al menos, la policía puede perseguir a los niños vagos», ${ }^{105}$ protes-

\footnotetext{
${ }^{102}$ Newland, Buenos Aires no es Pampa, 149.

${ }^{103}$ Informe anual de la Comisión de Educación (1858). XII. Esto difiere ligeramente de la descripción ofrecida en Federico Basualdo y Estela Pagani, La educación pública. Del Municipio a la Nación (1857-1886), vol. 1 (2009), 12, según la cual la ciudad de Buenos Aires «depositó informalmente» la administración en el Departamento General de Escuelas de la Provincia.

${ }^{104}$ Newland, Buenos Aires no es Pampa, 160.

${ }^{105}$ Citado en Juan P. Ramos, Historia de la instrucción primaria en la República Argentina (1810-1910), vol. 1. (Buenos Aires: Peuser, 1910), 103.
} 
tó-, otro decreto del 29 de noviembre de 1862 decidió que las escuelas primarias tenían que ser inspeccionadas por la Universidad. ${ }^{106}$

Para consternación de Sarmiento, la separación del Departamento de Escuelas de la Universidad y su reinserción en el aparato estatal como un Consejo de Instrucción Pública, decidido el 5 de octubre de 1864, ${ }^{107}$ fueron seguidas por la designación de Marcos Sastre, quien se opuso a algunos de los puntos de vista de Sarmiento sobre la vigilancia policial escolar como Inspector General de Escuelas. ${ }^{108}$ No sólo sostuvo Sartre esta posición crucial en la burocracia educacional, sino que también asumió la dirección de la restablecida escuela normal para la formación de maestros en 1865. La suerte de Sastre fue efímera, porque renunció a su cargo de director de la escuela normal, tras lo cual publicó un polémico folleto sobre el estado de la educación pública en la provincia de Buenos Aires. ${ }^{109}$ Luis José de la Peña (1822-1907), el anterior ministro de asuntos exteriores y con una larga trayectoria en temas educacionales, fue el sucesor de Sarmiento como jefe del Departamento de Escuelas y también se convirtió en el sucesor de Sastre como director de la escuela normal para maestros. Tanto Sastre como De la Peña tuvieron que enfrentar las opiniones, sobre todo negativas, acerca de sus políticas, publicadas en los influyentes Anales de la Educación Común, la voz impresa de Sarmiento y Juana Manso. ${ }^{110}$

En el nuevo Consejo de Instrucción Pública, responsable de las escuelas de toda la provincia y presidida por el jefe del Departamento de Escuelas, ${ }^{111}$ se encontraron los diferentes representantes de los puntos más conflictivos en materia educacional. Aparte de los conocidos liberales, como Juana Manso y Luis José de la Peña, el católico Pedro A. Goyena (1842-1892) colaboró en sus funciones. En este escenario, el breve mandato del católico-liberal José María Estrada (1842-1894), como sucesor

\footnotetext{
106 Salvadores, Instrucción primaria, 291.

${ }^{107}$ Ricardo Levene, Historia de la Provincia de Buenos Aires y formación de sus pueblos, vol. I (La Plata: Taller de Impresiones Oficiales, 1940), 451.

${ }^{108}$ Ramos, Historia de la instrucción primaria, 19.

${ }^{109}$ Véase carta de dimisión de Sastre, 9 de septiembre de 1865, publicada en Sastre, La educación popular, 10-11.

110 Salvadores, Instrucción primaria, 295.

111 «Decreto restableciendo el empleo de Gefe del Departamento de Escuelas y designando las atribuciones del consejo», 12 de abril de 1865, Rejistro oficial de la Provincia de Buenos Aires (1865), 74-75.
} 
de De la Peña a la cabeza del Departamento de Escuelas de la provincia entre 1869 y 1870, exacerbó las divisiones entre los administradores educacionales. ${ }^{112}$ Pero no sólo conflictos en el ámbito religioso fueron significativos. Cuando José de la Peña fue nombrado superintendente de escuelas por parte de la administración de la ciudad en 1870, un furioso folleto anticatólico fustigaba sus políticas y sus «despóticos» reglamentos escolares: «Existe un hombre desastroso para las escuelas de la Provincia de Buenos Aires, el actual director de escuelas de la ciudad de Buenos Aires», declaró el autor liberal. ${ }^{113}$ En general, surgieron más puntos de conflicto en los veinte años bajo escrutinio porque las viejas tensiones entre el Estado y la Sociedad de Beneficencia continuaron y otras nuevas se presentaron, algunas de ellas eran sobre las prioridades políticas divergentes definidas por Sarmiento y Sastre así como otros conflictos posteriormente presagiados sobre la educación religiosa en las escuelas.

Los folletos críticos, publicados desde 1865 en adelante, se enfocaron a veces en temas religiosos. Sastre, por ejemplo, argumentó de manera más enérgica a favor de la educación religiosa que Sarmiento: «separar la religion de la escuela seria el mayor de los errores sociales». ${ }^{114} \mathrm{Y}$ también fue evidente que una fracción liberal, contraria a los temas religiosos en las escuelas, emergió entre los educadores. Por ejemplo, Enrique de Santa Olalla, el subdirector de la escuela normal, ${ }^{115}$ cuya abierta desobediencia a las órdenes de Sastre había contribuido a la renuncia de este último como director de la restablecida escuela normal, estuvo definitivamente en contra de las políticas de tendencia católica introducidas por Santiago de Estrada como Jefe del Departamento de Escuelas en su breve mandato. El intelectual de origen boliviano y maestro de escuela primaria en Buenos Aires, Nicomedes Antelo (1829-1893), articuló su oposición sin ambigüedad, enfrentándose a las autoridades en las reuniones de los maestros de la ciudad. ${ }^{116}$ Sin embargo, el punto culminante del conflicto

\footnotetext{
${ }^{112}$ Levene, Historia de la Provincia de Buenos Aires, 457-458.

${ }^{113}$ Pedro Arno, El porvenir del país comprometido. El Sr. Sastre y las escuelas (Buenos Aires: Imprenta de ,El Nacional', 1871), 1.

${ }^{114}$ Sastre, La educación popular, 19.

115 «Decreto instituyendo una Escuela Normal de Preceptores, y nombrando Director y Sub-Director para la misma» Rejistro oficial, (1865), 133-134.

${ }^{116}$ Nicomedes Antelo, Contestación a la memoria sobre la educación común de Buenos Aires por el ex-sultán de las escuelas D. José M. Estrada (Buenos Aires: Imprenta Buenos Aires, 1870), 8. Sobre
} 
estaba aún por venir. A pesar de ciertas posiciones por demás claras, ${ }^{117}$ no existía aún un polo católico antagónico al liberalismo imperante en la ciudad. Posiciones vinculadas a la Iglesia Católica no tuvieron la autoridad suficiente para orientar de manera consistente y regular las acciones de aquellos católicos como Estrada y Sastre en el ámbito político-educacional. ${ }^{118}$ Sólo con el incendio del colegio jesuita por una muchedumbre anticlerical en 1875, las tensiones entre católicos y liberales llegaron a ser realmente intensas. ${ }^{119}$

Las visiones diferenciadas sobre lo popular se expresaron en varias políticas escolares en ese tiempo. Además del asunto de la participación popular en la fundación de escuelas, en el que Sarmiento y Sastre representaron puntos de vista opuestos, la cuestión de la formación de los maestros puso de manifiesto diferentes prioridades en las políticas escolares. Sólo después de que Sarmiento fuera enviado como ministro plenipotenciario a los Estados Unidos, se estableció la escuela normal, ${ }^{120}$ incluida su escuela de aplicación. ${ }^{121}$ Sarmiento reconocía en general la importancia de semejante institución para el perfeccionamiento del trabajo escolar. "Creo sin embargo que no estamos en estado de obtener beneficios de la formacion de estas escuelas, que absorberian sumas considerable sin producir resultados en proporcion». ${ }^{122} \mathrm{Su}$ escepticismo se basaba en su propia experiencia en Santiago de Chile como director de la primera escuela normal para maestros en Sudamérica. Vio malos resultados en la formación del maestro y cambios insignificantes en la configuración y el alcance de la instrucción primaria. ${ }^{123}$ Además, muchos

\footnotetext{
Antelo, véase Gabriel René Moreno, Nicomedes Antelo (Santa Cruz de la Sierra: Publicaciones de la Universidad, 1960).

${ }^{117}$ Martín Avelino Piñero, Principios de educación (Buenos Aires: Imprenta de Bernheim, 1855).

${ }^{118}$ Es sorprendente que el rol de la Iglesia Católica en el ámbito de la política y la prensa diaria fuera bastante marginal. Para las elecciones, véase Sábato, The Many and the Few, 60 y 140 respectivamente.

${ }^{119}$ Información detallada acerca este episodio en Sábato, The Many and the Few., 138-156.

120 «Decreto orgánico de la escuela normal de enseñanza elemental», 20 de junio de 1865, Recopilación de las leyes y decretos promulgados en Buenos Aires desde enero de 1841 hasta la fecha (1858): 252-267.

121 «Estatutos para rejir provisoriamente la Escuela Normal de Preceptores», 19 de julio de 1865, Rejistro oficial, (1865), 143-148, 148.

${ }^{122}$ Segundo informe, 36.

${ }^{123}$ Segundo informe, 37.
} 
maestros se encontraban entre los inmigrantes y creyó, por lo tanto, que la necesidad de contar con un cuerpo docente calificado podría ser satisfecha a partir de esa reserva de maestros importados. En su programa de carácter más político-educacional que profesionalista, todos los recursos debían ser dirigidos hacia la expansión de la enseñanza primaria. Sastre, por el contrario, en su programa de carácter preferentemente pedagógico-educacional, insistió en la creación de la escuela normal. ${ }^{124}$

Más allá de las discusiones de principio sobre la participación del pueblo, la religión y las estrategias en política escolar, una lucha por el predominio en materia de pedagogía se desató también en esos años. Marcos Sastre jugó en esto el papel más polémico. Ofreció su experiencia en materia educacional en todas partes. Antes de 1852 había ocupado cargos educacionales en la provincia de Entre Ríos, y, después de tener que dimitir al cargo de director de la escuela normal de la ciudad en 1865, ofreció sus pupitres y textos escolares al gobernador liberal de la provincia de Santa Fe, Nicasio Oroño. ${ }^{125}$ Se presentó asimismo como un precursor inigualable de la escolarización moderna y difundió un sistema completo de enseñanza, al que llamó sistema Sastre, por ser superior a todos los demás. Rechazó los sistemas asociados con «Lancáster, Pestalozi (sic), Jacotot, etc.» y afirmó que el suyo era "un sistema enteramente nuevo y original en su conjunto». ${ }^{126}$ Además, enfatizó que en su sistema «todo es argentino». ${ }^{127} \mathrm{Su}$ suposición de ser el precursor de la escuela moderna era un poco presuntuosa: «Era preciso crearlo todo, el banco, el libro, el discipulo y el maestro». ${ }^{128}$

Dos temas particularmente polémicos estaban relacionados con esta autoridad pedagógica naciente, y ambos formaban parte de la materialidad de la escuela: el mobiliario y los textos escolares. Mientras que Sarmiento había pedido pupitres en Nueva York para las dos escuelas

\footnotetext{
${ }^{124}$ Sastre, La educación popular, 24-26. Una vez establecida, la escuela normal padeció dificultades por un largo tiempo. El director Luis J. de la Peña, por ejemplo, renuncio a su salario y el dinero, compartido entre los demás maestros, hizo la mayor parte de los modestos ingresos del personal. Véase carta de Luis J. de la Peña, 9 de marzo de 1867, Índice del Registro Oficial de 1867, 126-128. ${ }^{125}$ Patricia Pasquali, La instauración liberal. Urquiza, Mitre y un estadista olvidado: Nicasio Oroño (Buenos Aires: Planeta, 2003), 187-188.

${ }^{126}$ Sastre, La educación popular, 8.

${ }^{127}$ Sastre, La educación popular, 15.

${ }^{128}$ Ibíd. Sastre, La educación popular, 9.
} 
modelo de la ciudad en los años 1857 y 1858, Sastre diseñó sus propios pupitres "argentinos», a los que elogiaba como un signo de modernización, racionalización y control. Sastre había logrado introducir sus escritorios escolares en la provincia de Entre Ríos en 1849 y, dos años más tarde, en la Escuela Normal en Buenos Aires. Éstos sustituyeron los escritorios norteamericanos en la Escuela Modelo de Catedral al Norte y se generalizaron en las escuelas de hombres de la ciudad. ${ }^{129}$ Sin embargo, Sastre tuvo que admitir que el suministro de sus escritorios escolares en las escuelas de la ciudad había conducido a una reducción del número de alumnos en las escuelas debido al espacio dejado entre los escritorios y las dimensiones del nuevo mobiliario. ${ }^{130}$ Este efecto de los nuevos pupitres se encontraba en franca contradicción con el énfasis explícito de Sarmiento en la rápida extensión de la escolarización primaria.

El hecho de que los intereses pecuniarios jugaran un papel importante en estas luchas por la autoridad pedagógica fue incluso más acentuado en el asunto de los textos escolares. Ya en 1854, el rector de la Universidad de Buenos Aires, José Barros Pazos, había recomendado en un decreto la introducción de los métodos de Sastre, especialmente para la lectura. ${ }^{131}$ Un año más tarde, cuando Sastre, ahora como Inspector General de Escuelas, publicó un libro elemental de ortografía, el que también agradó a Barros Pazos, Sarmiento, el nuevo Jefe del Departamento de Escuelas, detuvo su implementación, supuestamente por ser demasiado elevado para la instrucción primaria. ${ }^{132}$ A pesar de que Sastre preparó una edición abreviada y más económica, Sarmiento rechazó la obra nuevamente, presumiblemente porque el libro contradecía sus propias propuestas radicales a favor de una simplificación consistente de la ortografía castellana. ${ }^{133}$ El propio Sarmiento había escrito un manual de lectura que también fue recomendado para las escuelas, convirtiéndose

\footnotetext{
${ }^{129}$ Marcos Sastre, Catálogo analítico de las obras de D. Marcos Sastre (Buenos Aires: Ostwald y Martínez,1881), 15. Véase también, Marcos Sastre, Guia del Preceptor (Buenos Aires: Librería de D. Pablo Morta, 1862), 36.

${ }^{130}$ Sastre, Catálogo analítico de las obras de D. Marcos Sastre, 6. Una descripción detallada de los pupitres introducidos por Sarmiento en la Escuela Modelo se encuentra en Sarmiento, Informe del comisionado especial, 7-9.

${ }^{131}$ Sastre, Catálogo analítico de las obras de D. Marcos Sastre, 87.

${ }^{132}$ Sastre, Catálogo analítico de las obras de D. Marcos Sastre, 89.

${ }^{133}$ Sastre, Catálogo analítico de las obras de D. Marcos Sastre, 90.
} 
en un competidor de Sastre en el mercado de los textos escolares. ${ }^{134}$ Sarmiento, consultado acerca de libros escolares a adquirir por la ciudad en 1859, recomendó los de la editorial neoyorquina Appleton e ignoró completamente los diversos textos escolares escritos por Sastre ${ }^{135}$ y esto a pesar de que el propio Appleton reconocía que sus textos no eran aún lo suficientemente adecuados para Sudamérica y prometía una mejora al respecto en próximas ediciones. ${ }^{136}$

En 1865, cuando Sastre paso a ser director de la escuela normal local, rumores políticos afirmaban que la aprobación general de los libros de Sastre en las escuelas era el resultado del favoritismo político, una sospecha que Sastre rechazó rotundamente. ${ }^{137}$ Esto dio lugar a la emisión de un decreto que prohibía todos los intereses económicos de los funcionarios públicos en la provisión de libros escolares. ${ }^{138}$ Esta fue una de las causas explícitas de la renuncia de Sastre a la dirección de la Escuela Normal.

En el largo plazo, las creaciones pedagógicas de Sastre prevalecieron sobre otros libros escolares y propuestas didácticas. La escuela de la parroquia de Monserrat, por ejemplo, seguía el método Sastre para aritmética. ${ }^{139}$ La estadística de 1862 muestra que los textos Anagnosia ${ }^{140}$ y ortografía de Sastre eran los preferidos tanto por la reglamentación («horario») como por los maestros. ${ }^{141}$ A pesar de que evidentemente se

${ }^{134}$ El manual y la instrucción para maestros habían sido publicados en Chile. Véase Domingo Faustino Sarmiento, Instruccion para los maestros de escuela, para enseñar a leer por el método gradual de lectura (Imprenta de Julio Belin: Santiago, 1849).

${ }^{135}$ Sarmiento, Compra de libros escolares, 25 de enero de 1859. Archivo Histórico de la Ciudad de Buenos Aires: AH Buenos Aires, C7-1859, reproducido en Basualdo y Pagani, La educación pública, vol. 1, 33-35.

${ }^{136}$ Véase la carta de Appleton a Sarmiento, 3 de abril de 1860. Museo Histórico Sarmiento - Archivo Histórico, N. ${ }^{\circ} 4705$.

${ }^{137}$ Véase «Adopcion de los testos y métodos de D. Marcos Sastre», publicado en Sastre, La educación popular, 85-95.

138 «Decreto prohibiendo á los empleados en el ramo de instruccion primaria todo interes pecuniario en la provisión de testos», 19 de agosto de 1865, Rejistro oficial, (1865), 158-159.

${ }^{139}$ Resultados de los exámenes. Parroquia de Monserrat, 30 de junio de 1857. Archivo Histórico de la Ciudad de Buenos Aires, AH Buenos Aires, C7-1857, transcripto en Basualdo y Pagani, La educación pública, vol. 1, 27-30, 28.

${ }^{140}$ Originalmente publicado en 1849 , el manual fue editado muchas veces, incluso en el siglo Xx.

${ }^{141}$ Informes sobre las escuelas municipales y de ambos sexos. Materias que se enseñan y métodos que se utilizan, 1862. Archivo Histórico de la Ciudad de Buenos Aires, AH Buenos Aires, C7-1862, reproducido en Basualdo y Pagani, La educación pública, vol. 1, 43. 
habían distribuido materiales y textos sobrantes, originalmente importados desde Estados Unidos para las escuelas modelo, en las otras escuelas municipales, ${ }^{142}$ cuando la ciudad de Buenos Aires hizo un relevamiento de los libros autorizados y en uso en las escuelas en 1872, Sastre aún figuraba en los listados con la Anagnosia, los cuadros murales que la acompañaban, el Tempe Argentino, el método de caligrafía inglesa, las lecciones de aritmética, de gramática y de ortografía. ${ }^{143}$ El proyecto de reglamento de escuelas de la ciudad de 1871, formado por una comisión de seis preceptores de la ciudad entre los cuales figuraba el liberal Nicomedes Antelo, estableció en su artículo 17 que «los maestros podrán usar los testos que á su juicio correspondan mejor al éxito del programa». ${ }^{144}$ Más allá de esta reglamentación, todos estos textos de Sastre fueron confirmados como aprobados en las reglamentaciones escolares del mismo año. ${ }^{145}$ Si los maestros de la ciudad de Buenos Aires fueron más susceptibles a las posiciones de Sarmiento o a las de Sastre no es fácil de evaluar. En el plano pedagógico, respetaban la obra de Sastre en la sistematización del aprendizaje y la enseñanza; pero también reconocieron los aportes didácticos de Sarmiento como significativos. ${ }^{146}$ En general, el conflicto sobre el negocio relacionado con el suministro de textos escolares a las escuelas exacerbó los debates educacionales. Cuando los maestros liberales se opusieron a las políticas del católico Santiago de Estrada en 1870, una acusación contundente fue el hecho de que su hermano poseía la principal imprenta de libros escolares en la ciudad. ${ }^{147}$

Las políticas erráticas y los conflictos sobre la autoridad pedagógica no afectaron la expansión de la matrícula escolar. Sin embargo, la

${ }^{142}$ Carta de la Comisión de Educación de la Ciudad de Buenos Aires a Sarmiento, 19 de diciembre de 1857. Museo Histórico Sarmiento - Archivo Histórico, N. ${ }^{\circ} 4921$.

143 «Relacion de los textos en uso en las Escuelas Municipales», 1872. Archivo Histórico de la Ciudad de Buenos Aires, AH Buenos Aires, C9-1872, reproducido en Basualdo y Pagani, La educación pública, vol. 1, 70-71.

144 «Informe de Marcos Sastre sobre el programa y reglamento para las escuelas municipales», 20 de junio de 1871. Archivo Histórico de la Ciudad de Buenos Aires, AH Buenos Aires, C49-1871, reproducido en Basualdo y Pagani, La educación pública, vol. 1, 63-68, 65.

${ }^{145}$ Programa y clasificación de la enseñanza primaria elemental con arreglo al reglamento de las escuelas municipales de la ciudad de Buenos-Aires (Buenos Aires: Coni, 1872). Véase también Reforma de la enseñanza primaria (Buenos Aires: Imprenta, litografía y fundición de tipos, 1871).

${ }^{146}$ Joaquín Alarcón, Educación primaria en la escuela municipal de la Parroquia del Pilar (Buenos Aires: Argentina de «El Nacional», 1862), 6.

${ }^{147}$ Antelo, Contestación a la memoria sobre educación, 10. 
asistencia escolar a las escuelas públicas representaba sólo la mitad de todos los niños que asistían a la escuela primaria, ya que las escuelas privadas no sólo eran numerosas, sino que éstas parecían absorber la demanda creciente de escolarización que las escuelas públicas por sí solas no podían incorporar. ${ }^{148} \mathrm{Si}$ este proceso de expansión era acorde con un aumento general de la población infantil, el avance porteño fue más rápido que en cualquier otro lugar del país e incluso se pudo contrarrestar en gran medida el crecimiento exponencial de la población local durante estos años. ${ }^{149}$ A pesar de esta notable expansión, existió también un traspaso perceptible de niños provenientes de familias adineradas de las escuelas privadas a las públicas, una tendencia que se fortaleció en las décadas siguientes hasta 1930 y que específicamente se explica debido a la creación de las escuelas modelo equipadas con pupitres norteamericanos y abundantes materiales de enseñanza. A pesar del hecho de que uno de los aspectos más destacados de la nueva política educacional posterior a 1853 fue la construcción de nuevos edificios escolares, ${ }^{150}$ Sastre criticaba aún en 1865 que, de las 46 escuelas públicas de la ciudad, solo cuatro contaban con edificios adecuados. ${ }^{151}$

La expansión y el mejoramiento de la educación popular en la ciudad de Buenos Aires coincidió con el retroceso de la auspiciosa participación popular registrada al inicio en materia de escolarización. Dos desarrollos diferentes muestran las dinámicas contradictorias de este cambio. En primer lugar, las dos iniciativas más significativas de participación popular en la creación y la conservación de las escuelas-modelo, una alentadora promulgación del programa de regeneración de Sarmiento, fallaron en tanto escuelas sostenidas por la sociedad civil. La primera escuela modelo, al sur de la Catedral, perdió algunos de sus partidarios y rápidamente, en 1860, tuvo dificultades para operar sin el pago de matrícula. La tan deseada participación de los ciudadanos en la fundación, mantenimiento

\footnotetext{
${ }^{148}$ Para 1864, véase "Informe de 1860», Anales de la educación común en la República Argentina III, 26 (1865): 17-19, 17 (1864). Los primeros datos estadísticos sobre las escuelas privadas en la ciudad fueron recolectados solamente en 1858. Véase Segundo informe, 22.

${ }^{149}$ Véanse los datos estadísticos para todas las provincias de la ciudad de Buenos Aires de 1850 a 1895 en Alejandro Eujanián, «La cultura: público, autores y editores», Liberalismo, estado y orden burgués (1852-1880) (1999), 545-605, 549-550.

${ }^{150}$ Véase la creación de un fondo específico para este propósito en la ley del 31 de Agosto de 1858, en Registro oficial del gobierno de Buenos Aires. Año de 1858, vol. 37 (1858), 68-70.

${ }^{151}$ Sastre, La educación popular, 56.
} 
e inspección de las escuelas era por demás incompleta. Por ejemplo, el señor Anacarsis Lema, examinador voluntario, notificó no poder presenciar los exámenes de la escuela de la Parroquia Catedral al Sur "por sus ocupaciones», mientras Francisco Monasterio aludía a cuestiones de salud. ${ }^{152}$ En la escuela modelo al norte de la Catedral, «las obligaciones asumidas por el vecindario nunca fueron cumplidas a pesar de todos los esfuerzos hechos durante cinco o mas años». En general, la escuela modelo «nunca había superado la condición de [ser] una «simple escuela privada». ${ }^{153}$ Fue exactamente esta escuela la que fue asumida por el gobierno provincial en 1864 como «escuela normal», lo que presumiblemente fue asociado con ayuda financiera adicional y, al mismo tiempo, condenó a la insignificancia las suscripciones anuales del vecindario para su financiación. ${ }^{154}$

En segundo lugar, las organizaciones ciudadanas creadas para el apoyo y el mejoramiento de las escuelas disminuyeron su activismo por la educación primaria. Las primeras iniciativas impulsadas por ciudadanos comunes (aunque, en muchos casos, notables) fueron gradualmente reemplazadas por actores más especializados. Bajo Sarmiento, una Sociedad para la propagación de la educación primaria se estableció en 1863, probablemente siguiendo el modelo de la sociedad similar fundada en Santiago de Chile en 1856 y en estrecha similitud con el carácter de las suscripciones populares en los vecindarios. La nueva sociedad desapareció un año más tarde junto con la dimisión de Sarmiento al Departamento de Escuelas. ${ }^{155}$ Organizaciones educacionales más enfocadas en lo profesional tomaron la delantera. Por ejemplo, una Sociedad de Educación existía desde 1870, a la cual se asociaron muchos de los destacados educacionistas como Sastre, Santa Olalla, Antelo y De la Peña. ${ }^{156}$ En 1872, una Sociedad Pestalozzi surgió bajo el liderazgo de Juana Manso y Nicomedes Antelo, lo que implicó un claro

\footnotetext{
152 «Informe sobre dia de examen». Parroquia Catedral al Sud, 6 de Julio de 1857, Archivo Histórico de la Ciudad de Buenos Aires, AH Buenos Aires, C7-1857, transcripto en Basualdo y Pagani, La educación pública, vol. 1, 20-21, 20.

${ }^{153}$ Informe del Departamento de Escuelas (1866), 32.

${ }^{154}$ Newland, Buenos Aires no es Pampa, 163-164.

155 «Medidas y decretos concernientes a la Educación por el Gobierno Provincial de Buenos Aires», Anales de la educación común en la República Argentina III, 26 (1865): 25-27, 26.

${ }^{156}$ Véase «Sociedad de educación», La enseñanza libre en las escuelas del pueblo, I (1) (1870): 9-10.
} 
desafío para el «sistema Sastre», que se definía asimismo como puramente nacional y que había sido influyente hasta ese entonces en la ciudad. ${ }^{157}$

La Sociedad de Educación siguió los postulados de Sarmiento en lo que respectaba a la necesidad de implicar al pueblo en la provisión de educación popular: «el pueblo tiene que ocuparse de la educacion del pueblo», porque este era «un gran principio democrático». ${ }^{158}$ Esta formulación fue incluso adoptada en los estatutos de la sociedad. ${ }^{159}$ En la publicación vinculada a esta sociedad, se privilegiaba el aporte económico de la sociedad civil como una forma de apoyo a las escuelas públicas: «Las escuelas estatales son insuficientes incluso en los paises mas cultivados». ${ }^{160}$ Y agregaban: "No es el gobierno el que esta destinado a ser el promotor de la generalizacion de las escuelas; puede hacer muchas cosas, por cierto, pero resultados magníficos no dependen ni de su accion ni de su iniciativa». ${ }^{161}$ Hombres generosos fueron convocados para fomentar la acción de las fuerzas individuales en la tarea común de expandir la escolarización. Pero estas apelaciones liberales para una mayor participación cívica en educación se desvanecieron en las décadas siguientes, y la formación de una esfera pública vinculada a la educación en la ciudad no convergió, después de todo, con el ideal de los consejos escolares locales y la participación integral que Sarmiento había concebido. Quizás no sólo por la ascendencia de Sastre en la dirección de las escuelas porteñas, sino por los muy sobrios intentos de participación popular, Juana Manso lamentaba en una carta a Sarmiento en 1866 «nuestras derrotas». ${ }^{162}$

\section{LIBERALISMO CLÁSICO Y EDUCACIÓN PRIMARIA POPULAR EN ARGENTINA}

Los resultados de los experimentos de participación popular en el gobierno del sistema escolar no fueron ni positivos, ni concluyentes. No

\footnotetext{
${ }^{157}$ Lewcowicz, Manso, 140.

${ }^{158}$ Intervención de Mr. Hernández en la reunión de la «Sociedad de educación», La enseñanza libre en las escuelas del pueblo, I (2), (1870): 25-27, 26.

${ }^{159}$ Reglamento de la Sociedad de Educación (1870).

160 «Un deber social», La enseñanza libre en las escuelas del pueblo, I (1), (1870): 2-3, 2.

161 «Un deber social», 3.

${ }^{162}$ Carta de Juana Manso a Sarmiento, 26 de agosto de 1866. Museo Histórico Sarmiento - Archivo Histórico, N. ${ }^{\circ} 7431$.
} 
obstante, Sarmiento continuó luchando por un sistema escolar donde la parte «decente» del pueblo tenía que jugar un papel preponderante en su administración. Después de concluido su mandato como presidente del país en 1874, regresó a la política en la provincia de Buenos Aires. Su modelo de gobierno escolar basado en los consejos escolares locales fue adoptado por los órganos legislativos de la Provincia en 1875 y fue criticado por otros educadores de la época, lo que condujo con el tiempo a un cambio hacia un modo más burocrático de regulación educacional desde la década de 1880 en adelante. ${ }^{163}$

Otros casos de participación popular fueron para Sarmiento indicios de una naciente civilidad moderna, como en el pequeño pueblo de Chivilcoy, donde formas modernas de participación política y ciudadana parecían florecer. Su confianza en las posibilidades de regeneración social y política no resultó afectada por los acontecimientos más bien discontinuos y desalentadores en la ciudad de Buenos Aires. Los significados atribuidos al pueblo parecían haber favorecido algunos aspectos de las políticas educacionales sobre otros. El enfoque más optimista, apoyado por Sarmiento, consideró al pueblo desde un punto de vista muy normativo, pero político, si bien reduciendo el pueblo a las clases educadas e «inteligentes». En su opinión, serían estos grupos los llamados a fraguar la gran empresa de la educación general de la población. Una doble tarea adquirió de este modo prioridad: la consecuente expansión de las escuelas primarias modernas y la sustancial implicación del pueblo en este proyecto, siendo esta última una experiencia educativa colectiva imbuida en el espíritu de civilidad. Esta visión política del pueblo guiaba también posicionamientos como la oposición a la escuela normal de la ciudad por ser onerosa y, por ello, contraproducente para una expansión forzada de la escolarización. Asimismo, amén de otros aspectos técnicos, medicinales y pedagógicos, este énfasis en la expansión escolar como urgencia política podía afectar incluso decisiones como el tipo de banco escolar de preferencia, aquí oponiéndose a los bancos diseñados por Sastre que por su tamaño y disposición disminuían el número de alumnos por clase.

La visión más pesimista del pueblo y lo popular sostenida por Sastre implicaba una despolitización de la política escolar, aunque el sentido

${ }^{163}$ Pablo Pineau, La escolarización en la provincia de Buenos Aires (1875-1930) (Buenos Aires: FLACSO/ CBC-UBA, 1997), 35-44. 
político de lo escolar estuviera presente. Su visión cauta y hasta escéptica implicaba retrotraer la participación popular en la expansión, mantenimiento e inspección de las escuelas a favor de una autoridad pedagógica de nuevo cuño y que convenientemente él mismo representaba. Esto también pudo conducir a sucesos curiosos como el mencionado «sistema Sastre» que presumía ser superior a todos los existentes, y al descenso del número de los estudiantes en las escuelas como consecuencia de los nuevos pupitres escolares. Aunque Sarmiento también admitió el importante papel del mobiliario para una pedagogía racionalizada y eficaz, nunca habría sacrificado la expansión de la matrícula en nombre de los nuevos muebles escolares. En este sentido, las variaciones de las políticas educativas, parcialmente basadas en los diferentes significados del pueblo, alcanzaron aspectos muy específicos de las nuevas políticas escolares durante el periodo clásico del liberalismo.

El fracaso de Sarmiento en la construcción de un modelo más participativo de financiamiento y regulación escolar no puede atribuirse meramente a una falta de convicción o a contradicciones internas de su programa. Si el liberalismo como una forma de gobernabilidad moderna de las sociedades es más que el nombre de un partido político en particular, Sarmiento y el proyecto de activismo social favorecido por él fracasaron debido a dos aspectos relacionados entre sí. Primero, los problemas de la política educativa liberal mostraban muchas semejanzas con los dilemas del campo político. En este último, el interés y la participación política existían y eran efectivas, pero sus medios de expresión eran sólo asociados a las políticas institucionales, como estaba establecido en el programa de una forma de gobierno liberal. Asimismo, reuniones en las calles, actos y rebeliones abiertas mostraron que estos canales de participación eran preferidos por una gran parte de la población por sobre los procesos electorales previstos en los diseños institucionales. De manera similar a la esfera política, donde sólidas ideas liberales y prácticas políticas confusas y fraudulentas coexistieron, la política escolar en Buenos Aires parecía muy de principios y doctrinal, pero la realidad de las actividades cotidianas en el ámbito educacional permaneció asociada a pequeños grupos de interés y a la construcción de una burocracia específica con muy poco interés en compartir poder con grupos ciudadanos organizados. ${ }^{164} \mathrm{Se}-$

${ }^{164}$ Sarmiento mismo percibió esta dificultad. Eujanián, «La cultura», 551. 
gundo, incluso estas clases educadas, siendo el elemento de apoyo de un primer auge exitoso de actividad ciudadana organizada, mostraron poco interés en el largo plazo y su participación pareció más bien exhibir el predominio duradero de conceptos tradicionales de notabilidad y visibilidad en la esfera pública de la «gente decente» que la participación sustantiva en la cotidianeidad del gobierno escolar. En particular debido a estas características de la cultura política liberal clásica de la ciudad de Buenos Aires, la institucionalización de escuela primaria porteña para el pueblo seguiría un patrón burocrático muy diferente y Buenos Aires, definitivamente, no se convertiría en un segundo San Francisco.

\section{Nota sobre los autores}

Marcelo Caruso es Catedrático de Historia de la Educación en el Instituto de Ciencias de la Educación de la Universidad Humboldt, Berlín/Alemania. Diploma en Ciencias de la Educación de la Universidad de Buenos Aires (1993), Doctorado en Pedagogía de la Universidad de Múnich (2001) y Habilitación de la Universidad Humboldt en Berlín (2008). Es director de la Revista de Pedagogía (Zeitschrift für Pädagogik) y miembro de los consejos editoriales de Paedagogica Historica, Anuario Alemán de Historia de la Educación (Jahrbuch für Historische Bildungsforschung) y del Nordic Journal of Educational History, entre otros. Actual proyecto de investigación: «La burocratización de los agrupamientos: Dinámica de la innovación en la introducción de la escuela graduada en la educación obligatoria (Prusia, Estados Unidos, España, 1830-1930)».

Marco A. Rodríguez Wehrmeister es docente en las áreas de Sociología de la Educación e Historia de la Educación, Instituto de Sociología de la Facultad de Humanidades, Universidad de Valparaíso, Chile. M.A en Sociología (2004), Universidad Libre de Berlín (FU). Desde 2014, estudiante de doctorado bajo la supervisión del Prof. Dr. Marcelo Caruso, Departamento Historia de la Educación, Instituto de Ciencias de la Educación de la Universidad Humboldt de Berlín, Alemania y becario en el marco del Convenio de Desempeño para las Humanidades, Artes y Ciencias Sociales de la Universidad de Valparaíso. Tema de la investigación: «La construcción chilena del modelo de educación norteamericano: Maestros comisionados, expertos e innovación pedagógica en la educación primaria (1902-1931)». 


\section{Archivos}

Archivo del Museo Histórico Sarmiento.

Archivo del Museo Mitre.

Archivo Histórico de la Ciudad de Buenos Aires.

\section{Publicaciones periódicas}

Álbum de Señoritas.

Anales de la Educación Común.

La enseñanza libre en las escuelas del pueblo.

Registro oficial del gobierno de Buenos-Aires.

\section{Referencias}

Alarcón, Joaquín. Educación primaria en la escuela municipal de la Parroquia del Pilar. Buenos Aires: El Nacional, 1862.

AlBERDI, Juan Bautista. Organización de la confederación argentina. Besançon: Beuille, 1858.

Antelo, Nicomedes. Contestación a la memoria sobre la educación común de Buenos Aires por el ex-sultán de las escuelas D. José M. Estrada. Buenos Aires: Imprenta Buenos Aires, 1870.

ARno, Pedro. El porvenir del país comprometido. El Sr. Sastre y las escuelas. Buenos Aires: Imprenta de El Nacional, 1871.

Basualdo, Federico y Estela Pagani, eds. La educación pública. Del Municipio a la Nación (1857-1886). Buenos Aires: Dirección General de Patrimonio e Instituto Histórico, 2009.

BonAUdo, Marta. «Los grupos dominantes entre la legitimidad y el control». In Liberalismo, estado y orden burgués (1852-1880), edited by Marta Bonaudo, 27-96. Buenos Aires: Sudamericana (1999).

BotanA, Natalio. La tradición republicana. Buenos Aires: Editorial Sudamericana, 1997.

BRANDARIZ, Gustavo A. «La actividad masónica en la educación argentina (18101910)». Temas de patrimonio cultural 8 (2003): 33-51.

Bustamente Vismara, José. «Entre el decir y el hacer. Sarmiento, los municipios y la administración de las escuelas». Estudios de Teoria Literaria 1 (1), (2012): 27-34.

CARUSO, Marcelo. «Literacy and Suffrage. The politicisation of schooling in postcolonial Hispanic America (1810-1850)». Paedagogica Historica 46 (4), (2010): 463-478. 
Catecismo politico al uso de las escuelas de Buenos Aires. Buenos Aires: Imprenta del Orden, 1866.

Chamosa, Oscar. «To Honor the Ashes of Their Forebears: The Rise and Crisis of African Nations in the Post-Independence State of Buenos Aires, 18201860». The Americas 59 (3), (2003): 347-378.

De la Fuente, Ariel. Children of Facundo. Caudillo and Gaucho Insurgency During the Argentine State-Formation Process (La Rioja, 1853-1870). Durham \& Londres: Duke University Press, 2000.

Di Meglio, Gabriel. ;Viva el bajo pueblo! La plebe urbana de Buenos Aires y la política entre la Revolución de Mayo y el rosismo. Buenos Aires: Prometeo, 2006.

Dominguez, Luis L., ed. Escritos politicos, economicos y literarios, del doctor D. Florencio Varela. Buenos Aires: Imprenta de El Orden, 1859.

EUJANIÁN, Alejandro. "La cultura: público, autores y editores». In Liberalismo, estado y orden burgués (1852-1880), edited by Marta Bonaudo, 545-605. Buenos Aires: Sudamericana, 1999.

FERnÁndez Sebastián, Javier y Juan Francisco Fuentes, eds. Diccionario político y social del siglo XIX español. Madrid: Alianza, 2002.

Goldman, Noemí y Gabriel Di Meglio. «Pueblo/Pueblos». In Lenguaje y revolución. Conceptos políticos clave en el Río de la Plata, 1780-1850, edited by Noemí Goldman, 131-145. Buenos Aires: Prometeo, 2008.

González Bernaldo de Quirós, Pilar. Civilidad y política en los orígenes de la Nación Argentina. Las sociabilidades en Buenos Aires, 1829-1862. Buenos Aires: FCE, 2000.

HalPerin Donghi, Tulio. Una nación para el desierto argentino. Buenos Aires: CEAL, 1992.

Jalif de Betranou, Clara Alicia. «Luis José de la Peña, primer profesor de filosofía de la Universidad de Montevideo: sus lecciones de filosofía (1827)». Cuadernos americanos 3 (105), (2004): 138-144.

LETTIERI, Alberto. «De la "República de la Opinión” a la "República de las Instituciones”». In Liberalismo, estado y orden burgués (1852-1880), edited by Marta Bonaudo, 97-160. Buenos Aires: Sudamericana, 1999.

LeVEne, Ricardo. Historia de la Provincia de Buenos Aires y formación de sus pueblos, Tomo I. La Plata: Taller de Impresiones Oficiales, 1940.

Levene, Ricardo, ed. Fundación de escuelas públicas en la Provincia de Buenos Aires durante el gobierno escolar de Sarmiento (1856-1861; 1875-1881). La Plata: Talleres de Impresiones Oficiales, 1939.

LewcowICZ, Lidiy F. Juana Paula Manso (1819-1875). Una mujer del siglo XXI. Buenos Aires: Corregidor, 2000. 
MAnso, Juana. Curso graduado de instrucción en las escuelas públicas de Chicago. Para servir de modelo a las de la República Argentina. Buenos Aires: Imprenta Americana, 1869.

Moreno, Gabriel René. Nicomedes Antelo. Santa Cruz de la Sierra: Publicaciones de la Universidad, 1960.

NARODOwsKI, Mariano. «La expansión lancasteriana en Iberoamérica. El caso de Buenos Aires». Anuario del Instituto de Estudios Históricos y Sociales 9 (1994): 255-278.

- «El lado oscuro de la luna. El temprano siglo XIX y la historiografía educacional argentina». In Historia de la educación en debate, edited by Rubén Cucuzza, 269-280. Buenos Aires: Miño y Dávila, 1996.

- "Los libros de texto de pedagogía en la formación de docentes de Buenos Aires (1810-1830)». In Los manuales escolares como fuente para la historia de la educación en América Latina, edited by Gabriela Ossenbach Sauter y José Miguel Somoza Rodríguez, 83-94. Madrid: UNED, 2001.

NEwLAND, Carlos. "La educación primaria privada en la Ciudad de Buenos Aires (1820-1834)». Libertas 4 (1986): 25-38.

- Buenos Aires no es Pampa: la educación elemental porteña, 1820-1860. Buenos Aires: GEL, 1992.

ORÍA, Angela Inés. «Desafíos a la “educación popular”. Sarmiento en el Departamento de Escuelas, 1856-1862». PhD diss., Universidad de San Andrés, 2004.

Pasqual, Patricia. La instauración liberal. Urquiza, Mitre y un estadista olvidado: Nicasio Oroño. Buenos Aires: Planeta, 2003.

Pineau, Pablo. La escolarización en la provincia de Buenos Aires (1875-1930). Buenos Aires: FLACSO/ CBC-UBA, 1997.

PIÑERo, Martín Avelino. Principios de educación. Buenos Aires: Imprenta de Bernheim, 1855.

Puiggrós, Adriana. Sujetos, disciplina y currículum en los orígenes del sistema educativo argentino, 1884-1916. Buenos Aires: Galerna, 1990.

Ramos, Juan P. Historia de la instrucción primaria en la República Argentina, 1810-1910. Tomo 2. Buenos Aires: Peuser, 1910.

SÁBAto, Hilda. The Many and the Few. Political Participation in Republican Buenos Aires. Stanford: Stanford University Press, 2001.

SÁ e Melo Ferreira, Fátima. «Povo e povos no mundo ibero-americano». Jahrbuch für Geschichte Lateinamerikas 45 (2008): 245-274.

SÁEnz QuesadA, María. El estado rebelde. Buenos Aires entre 1850-1860. Buenos Aires: Editorial de Belgrano, 1982.

Salvadores, Antonino. La instrucción primaria desde 1810 hasta la sanción de la ley 1420. Buenos Aires: Talleres gráficos del Consejo Nacional de Educación, 1941. 
SARmiento, Domingo Faustino. De la educación popular. Santiago de Chile: Imprenta de Julio Belin i compañia, 1849.

- Instruccion para los maestros de escuela, para enseñar a leer por el método gradual de lectura. Santiago: Imprenta de Julio Belin, 1849.

- Comentarios de la constitucion de la Confederacion Arjentina. Santiago de Chile: Imprenta de Julio Belin, 1853.

- Educación común en el Estado de Buenos-Aires. Santiago de Chile: Imprenta de Julio Belin, 1855.

- Informe del comisionado especial para la creacion de una escuela modelo decretada por la Municipalidad de la Ciudad de Buenos Aires. Buenos Aires: Imprenta Argentina, 1857.

- Las escuelas: base de la prosperidad $i$ de la república en los Estados Unidos. Nueva York: s.d., 1865.

SASTRE, Marcos. Lecciones de arismética para las escuelas primarias de niños y niñas. Buenos Aires: Librería de Ortíz, 1854.

- Lecciones de gramática para la enseñanza primaria de niñas y niños. Buenos Aires: Librería de Pablo Morta, 1859.

- Guia del Preceptor. Buenos Aires: Librería de D. Pablo Morta, 1862.

- La educación popular en Buenos Aires. Buenos Aires: Librería de Morta, 1865.

- Catálogo analítico de las obras de D. Marcos Sastre. Buenos Aires: Ostwald y Martínez, 1881.

Szuchman, Mark D. "Childhood Education and Politics in Nineteenth-Century Argentina: The Case of Buenos Aires». Hispanic American Historical Review 70 (1), (1990): 109-138.

- «In Search of Deference: Education and Civic Formation in Nineteenth-Century Buenos Aires». In Molding the Hearts and Minds. Education, Communications, and Social Change in Latin America, edited by John A. Britton, 1-18. Wilmington: Scholarly Ressources, 1994.

Ternavasio, Marcela. La revolución del voto. Política y elecciones en Buenos Aires, 1810-1852. Buenos Aires: Siglo XXI, 2002.

VEIGA, Raúl. «La instrucción pública elemental y la organización nacional. Argentina, 1810-1880». In École et société en Espagne et en Amérique Latine (xviiie-xxe siècles), edited by Jean-René Aymes, Ève-Marie Fell y Jean-Louis Guereña 103-118. Tours: Publications de l'Université de Tours,1983.

Villavicencio, Susana. Sarmiento y la nación cívica. Ciudadanía y filosofías de la nación en Argentina. Buenos Aires: Eudeba, 2008. 